\title{
Traditional Japanese Kampo Medicine: Clinical Research between Modernity and Traditional Medicine_-The State of Research and Methodological Suggestions for the Future
}

\author{
Kenji Watanabe, ${ }^{1}$ Keiko Matsuura, ${ }^{1}$ Pengfei Gao, ${ }^{1}$ Lydia Hottenbacher, ${ }^{2}$ Hideaki Tokunaga, ${ }^{1}$ \\ Ko Nishimura, ${ }^{1}$ Yoshihiro Imazu, ${ }^{1}$ Heidrun Reissenweber, ${ }^{3}$ and Claudia M. Witt ${ }^{2}$ \\ ${ }^{1}$ Center for Kampo Medicine, Keio University School of Medicine, Shinjuku-ku, Tokyo, Japan \\ ${ }^{2}$ Institute for Social Medicine, Epidemiology and Health Economics, Charité University Medical Center, 10098 Berlin, Germany \\ ${ }^{3}$ Research Unit for Japanese Phytotherapy (Kampo), Department of Internal Medicine, University of Munich, Munich, Germany
}

Correspondence should be addressed to Claudia M. Witt, claudia.witt@charite.de

Received 12 October 2009; Accepted 13 May 2010

Copyright (C) 2011 Kenji Watanabe et al. This is an open access article distributed under the Creative Commons Attribution License, which permits unrestricted use, distribution, and reproduction in any medium, provided the original work is properly cited.

The Japanese traditional herbal medicine, Kampo, has gradually reemerged and 148 different formulations (mainly herbal extracts) can be prescribed within the national health insurance system. The objective of this article is to introduce Kampo and to present information from previous clinical studies that tested Kampo formulae. In addition, suggestions on the design of future research will be stated. The literature search was based on a summary, up until January 2009, by the Japanese Society of Oriental Medicine and included only those trials which were also available in either Pubmed or ICHUSHI (Japan Medical Abstracts Society). We included 135 studies, half of these studies $(n=68)$ used a standard control and 28 a placebo control. Thirty-seven trials were published in English [all randomized controlled trials (RCTs)] and the remaining articles were in Japanese only. The sample size for most studies was small (two-third of the studies included less than 100 patients) and the overall methodological quality appeared to be low. None of the studies used Kampo diagnosis as the basis for the treatment. In order to evaluate Kampo as a whole treatment system, certain aspects should be taken into account while designing studies. RCTs are the appropriate study design to test efficacy or effectiveness; however, within the trial the treatment could be individualized according to the Kampo diagnosis. Kampo is a complex and individualized treatment with a long tradition, and it would be appropriate for further research on Kampo medicine to take this into account.

\section{Background}

1.1. Historical Background. Japanese traditional herbal medicine (Kampo medicine) obtained the unique features observed today during its phase of long historical development in Japan. In Japan, the administration of crude herbal drug formulations dates back by more than 1500 years. Recent decades have seen a revival of Kampo medicine in medical practice, accompanied by a scientific reevaluation and critical examination of its relevance in modern health care [1].

The term "Kampo", which literally means "method from the Han period (206 BC to $220 \mathrm{AD}$ ) of ancient China", refers to its origin from ancient China. The basic therapeutic handbook for the application of herbal prescriptions was the Shang han lun. During the Edo-period from 1600 onwards, the specific Japanese characteristics of Kampo took shape. The seclusion of Japan from the outside world led to ever increasing differences from the predominantly Chinese concepts. The huge variety of the thousands of Chinese crude drugs was reduced to $\sim 300$, those being the most efficacious drugs which were subsequently combined into $\sim 300$ prescriptions. From a pragmatic point of view, Japanese physicians criticized the highly theoretical and speculative nature of Chinese medicine as being inadequate to meet the problems of every-day practice. The strongest critique came from Yoshimasu Todo in the 18th century who wrote: "In clinical medicine, we should only rely on what we actually have observed by examination of the patient". For Yoshimasu Todo, one way to gain data on 
the condition of the body was to examine the abdomen, for which he developed a refined palpation technique (fukushin) [2]. The results of the abdominal palpation should give additional clinical information in order to select the most appropriate herbal prescription for the patient. Yoshimasu Todo's pragmatic attitude and his abdominal palpation as a diagnostic procedure has had a strong influence on Kampo therapy right up until the present day [3].

It is not surprising that many Japanese physicians were drawn towards medical techniques from the West to improve their therapeutic options in surgery, but most of them continued to use traditional Kampo prescriptions for treating problems of internal medicine until the 19th century. At the end of the 19th century, it became obvious that for the urgent medical problems of that time, infectious diseases and acute surgical problems, Western medicine had better tools. The German system of medical education was adopted. In 1876, the government passed a regulation that all physicians were required to study Western medicine. The practice of Kampo was not forbidden but greatly inhibited and gradually declined [4]. However, after the Second World War, the first modern Kampo specialists carried on the traditions from the Edo-period. This revival of Kampo took place within a context dominated by modern Western medicine. The pragmatic and reductive approach of restricting Kampo therapy to clinically meaningful components helped to facilitate its gradual integration into modern medicine. Modern industrial society, in combination with longer life expectancy, has caused a shift in the predominant disease patterns, bringing to the therapeutic forefront chronic and degenerative diseases, functional and psychosomatic disorders and the multimorbidity of the elderly. These provide the main indications for the use of herbal drugs, not only with respect to treatment, but also for prevention [5].

Although rooted in Chinese tradition, Kampo medicine is not the same as modern traditional Chinese medicine (TCM). TCM emphasizes the traditional concepts of East Asian natural philosophy, such as Yin and Yang and the theory of the five elements. Japanese Kampo favors diagnostic methods that directly relate the symptoms to the therapy, bypassing speculative concepts. The vast array of crude drugs has been reduced in Kampo and also the quantity of each drug in the formulation is much lower. While Kampo still uses traditional prescriptions, TCM also tends to create new drug combinations [6].

1.2. Usage and Integration into Modern Medicine. Kampo traditional prescriptions have been included in the Japanese National Health Insurance drug list since 1971. A total of 148 Kampo herbal prescriptions are able to be funded to date. The application of Kampo has steadily increased and according to a survey by the Journal Nikkei Medical, more than $70 \%$ of physicians prescribe Kampo drugs today [7]. The Japan Society for Oriental Medicine is the biggest society for Kampo medicine and has 8600 members and 2600 certified board members. In 2001, Kampo education for medical students was incorporated into 'the model core curriculum' by the Japanese Ministry of Education, Culture, Sports, Science and Technology [6].

The development of modern ready-to-use forms was directly related to the enormous increase in Kampo usage, mainly as spray-dried granular extracts of the original formulae. They have increasingly replaced the traditional decoction of the crude drugs, even though they are also covered by the national insurance system. Besides being simple to administer, industrial production has enabled several other advantages. The quality control of the purity as well as toxicity is standardized in Japan, following the Japanese pharmacopoeia and internationally established regulations for Good Manufacturing Practice (GMP) and Good Laboratory Practice (GLP). The standardization of the main components has become possible and this is a precondition of clinical research. Today, extract preparations make up to $95 \%$ of the Japanese Kampo market.

In Western countries, herbal therapies originating in other cultural areas, mainly Chinese herbal medicine as part of TCM, are receiving increasing interest. In the USA, TCM is still far more visible than Kampo. The practitioners practice herbal therapy often in combination with acupuncture, which is often a mixture of Chinese, Japanese and Korean acupuncture styles. Kampo drugs are only available over the counter, meeting Japanese GMP criteria. Since Japanese pharmaceutical companies have started clinical trials in the USA, several drugs have already been registered as investigational new drugs (IND) by the Food and Drug Administration. Safety and toxicity data from Japan are generally accepted by the US and European agencies.

In Europe, especially in Germany, there is a long-term tradition of herbal medicine, and there is growing interest in Chinese phytotherapy and Japanese Kampo is also getting more and more attention. However, there is a shortage of doctors specialized in Japanese Kampo.

\subsection{Background of Kampo. Kampo is an individualized} treatment system where the overall condition of the patient and their constitution are of real importance; additionally, Kampo has a holistic therapeutic approach, as the mind and body are seen as one entity. The therapeutic aim is to relieve symptoms and to restore harmony in bodily functions. The treatment regime is based on symptoms. For the determination of the appropriate herbal prescription, the physician carries out a thorough investigation of the complaints and symptoms of the patient, including taking their temperature, examining sensation, weakness or sweating, symptoms which are not often primarily taken into account in conventional medicine. The physical examination includes abdominal palpation, tongue inspection and pulse diagnosis. This provides additional information concerning the state of the disease, by gathering the amount and distribution of $k i$ (vital energy), ketsu (blood) and sui (body fluid). The subjective complaints and the symptoms observed by the physician are combined to an individual symptom profile, a Kampo diagnosis (sho), which leads to the selection of the appropriate prescription [8]. It may happen that patients 
TABLe 1: Summary of Kampo clinical studies (1987-2007).

\begin{tabular}{lccccc}
\hline & RCT & Quasi-RCT & Cross-over design & $\begin{array}{l}\text { Comparative study } \\
\text { (non-randomized) }\end{array}$ & Total \\
\hline $\begin{array}{l}\text { Kampo versus either no } \\
\text { treatment or a different }\end{array}$ & 31 & 1 & 4 & 3 & 39 \\
$\begin{array}{l}\text { Kampo formula } \\
\text { Kampo versus placebo }\end{array}$ & 22 & 0 & 2 & 4 & 28 \\
$\begin{array}{l}\text { Kampo versus standard } \\
\text { treatment }\end{array}$ & 53 & 5 & 4 & 6 & 68 \\
\hline Total & 106 & 6 & 10 & 13 & 135 \\
\hline
\end{tabular}

with the same conventional diagnosis obtain different prescriptions (same diagnosis but different treatments), or patients with different conventional diagnoses are prescribed the same formula (same treatment for different diagnoses).

Japanese physicians with limited education in Kampo diagnostics tend to apply the formulations according to conventional Western diagnoses. This makes sense for some limited indications, if the formula for the Kampo sho is close to the conventional diagnosis. However, in most cases, the traditional individual approach, where each patient receives their appropriate prescription, is the preferred option. For example, diseases that are expected to respond to the formula Kakkonto are diagnosed as Kakkonto-sho and it naturally follows that Kakkonto is prescribed in such cases.

These special conditions have made clinical research in the field of Kampo medicine more complex than the research on conventional drugs. The World Health Organization West Pacific Regional Office (WHO/WPRO) has put considerable efforts into standardizing East Asian traditional medicine [9]. WHO headquarters is considering incorporating the international classification of Traditional Medicine, East Asia (ICTM EA) into International Classification of Diseases (ICD)-11. ICD-11 is planned to be finalized in 2014 and scheduled to be approved by the WHO assembly in 2015 . Japan proposes a double coding system of the ICD codes, that is, the conventional diagnosis code together with the traditional diagnosis (or pattern) code. This will allow integration into the conventional medical system without loosing the traditional information. The Kampo pattern (sho) codes have already been published in Japanese [10].

\section{Information Available on Clinical Research}

Our search was based on an evidence report of Kampo treatment made by the Japanese Society of Oriental Medicine (JSOM) which included 320 clinical trials between 1986 and 2008. [11]. This report includes Kampo trials available in the Cochrane register [12], ICHUSHI (Japan Medical Abstracts Society) [13] and the database from the Japan Kampo Medicines Manufacturer Association [14]. In this review only those studies were included, which used granulate formulations and were based on the drug regulation that was introduced in 1986. Liquid formulations and decoctions were excluded. Only peer-reviewed research from the JSOM database were included, which were also available in PubMed [15] or ICHUSHI [13]. A total of 135 trials, published between 1988 and 2007, were identified and summarized Table 1. These publications were extracted by two researchers fluent in both English and Japanese. Subsequently, they were discussed with two senior researchers (a Kampo specialist from Japan and a research methodologist from Germany). We classified Kampo clinical studies into three categories (Tables 2, 3, and 4):

(i) Kampo compared with either no treatment or different Kampo formula.

(ii) Kampo compared with placebo.

(iii) Kampo compared with standard treatment.

Among the 135 clinical studies, 106 were randomized controlled trials (RCTs), 6 quasi-RCTs and 10 were crossover studies. There were 13 non-randomized comparative studies. Among the 106 RCTs, 23 studies were placebocontrolled. More than two thirds of the studies used only Kampo as verum, whereas in 38 studies, Kampo was used in addition to the standard treatment. Almost half of the studies $(n=68)$ used a standard control, 28 used a placebo control, 24 had no treatment control and in 15, another Kampo formula was used as a control Table 1.

The sample size varied between 4 patients in the smallest study and 2069 patients in the largest. Most of the studies were small. Two thirds included less than 100 patients and the overall quality was low. Thirty-five trials were published in English and the remaining studies were in Japanese. The spectrum of diagnoses was diverse. The most common diagnosis was asthma (ICD J 45.0 and J 45.9), which was evaluated in nine studies. Many of the trials had low methodological quality (small sample size and unclear concealment) and thus a publication bias is to be expected. With respect to the methodology, it is interesting to note that in all studies summarized here, the treatment was based on the Western diagnosis only. A Kampo diagnosis was not mentioned in any of the trials. However, one trial seemed to be more individually based, using seven different Kampo formula in the verum group [134].

\section{Suggestions for Future Research}

3.1. Relevant Research Questions. The research available followed a Western approach and concentrated on single Western diagnoses treated with one Kampo formula. Since Kampo is a comprehensive and complex treatment system 


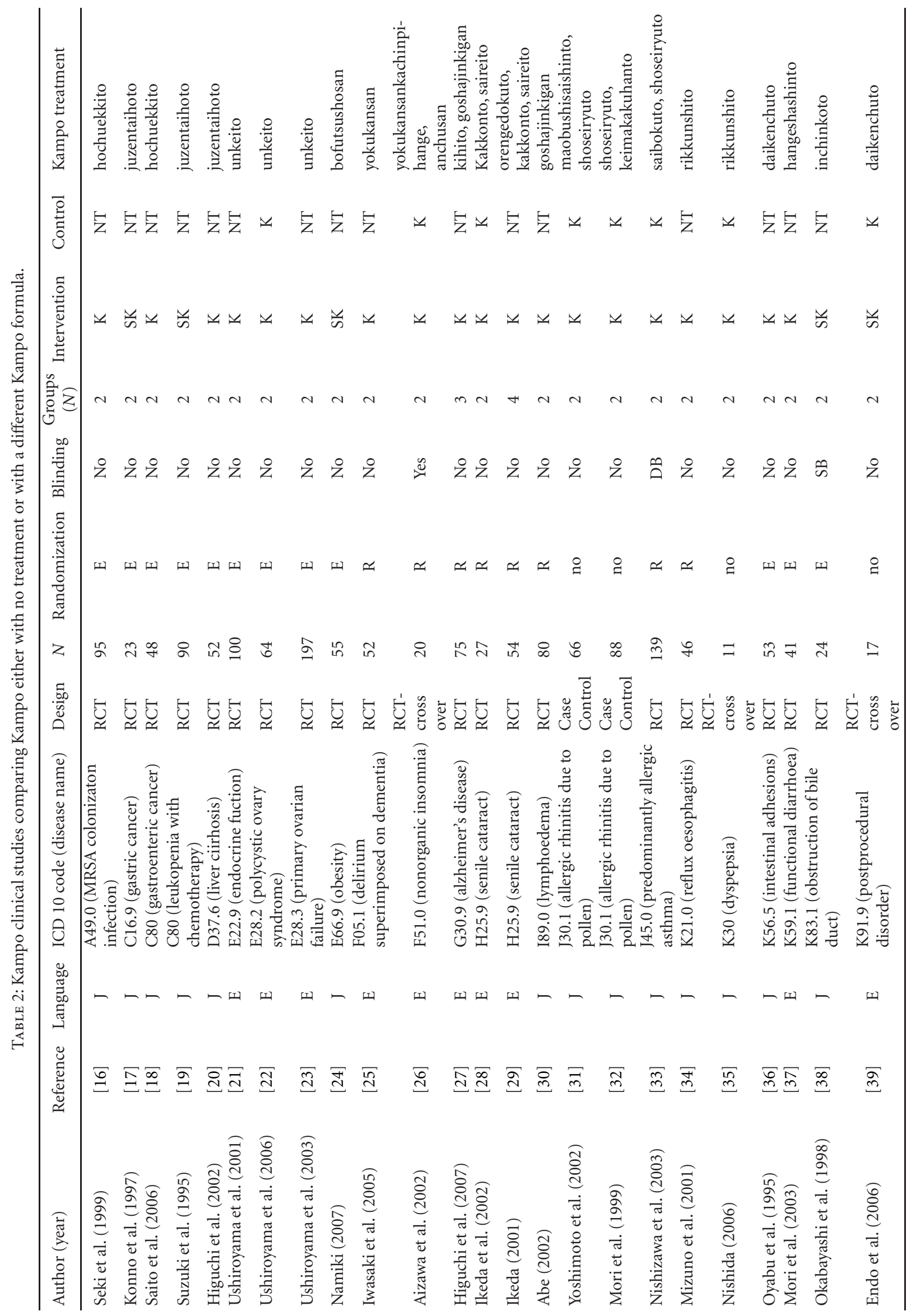




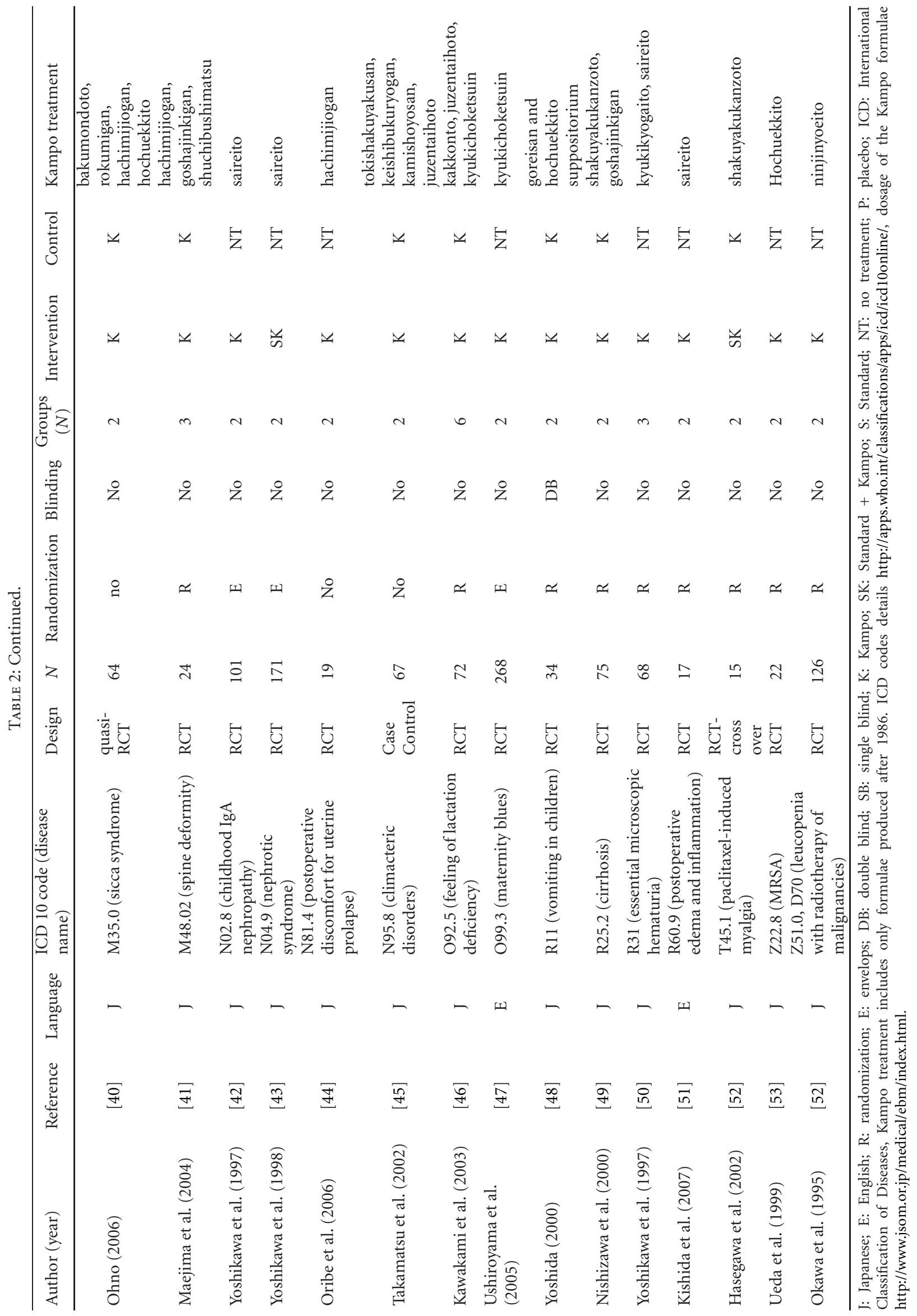




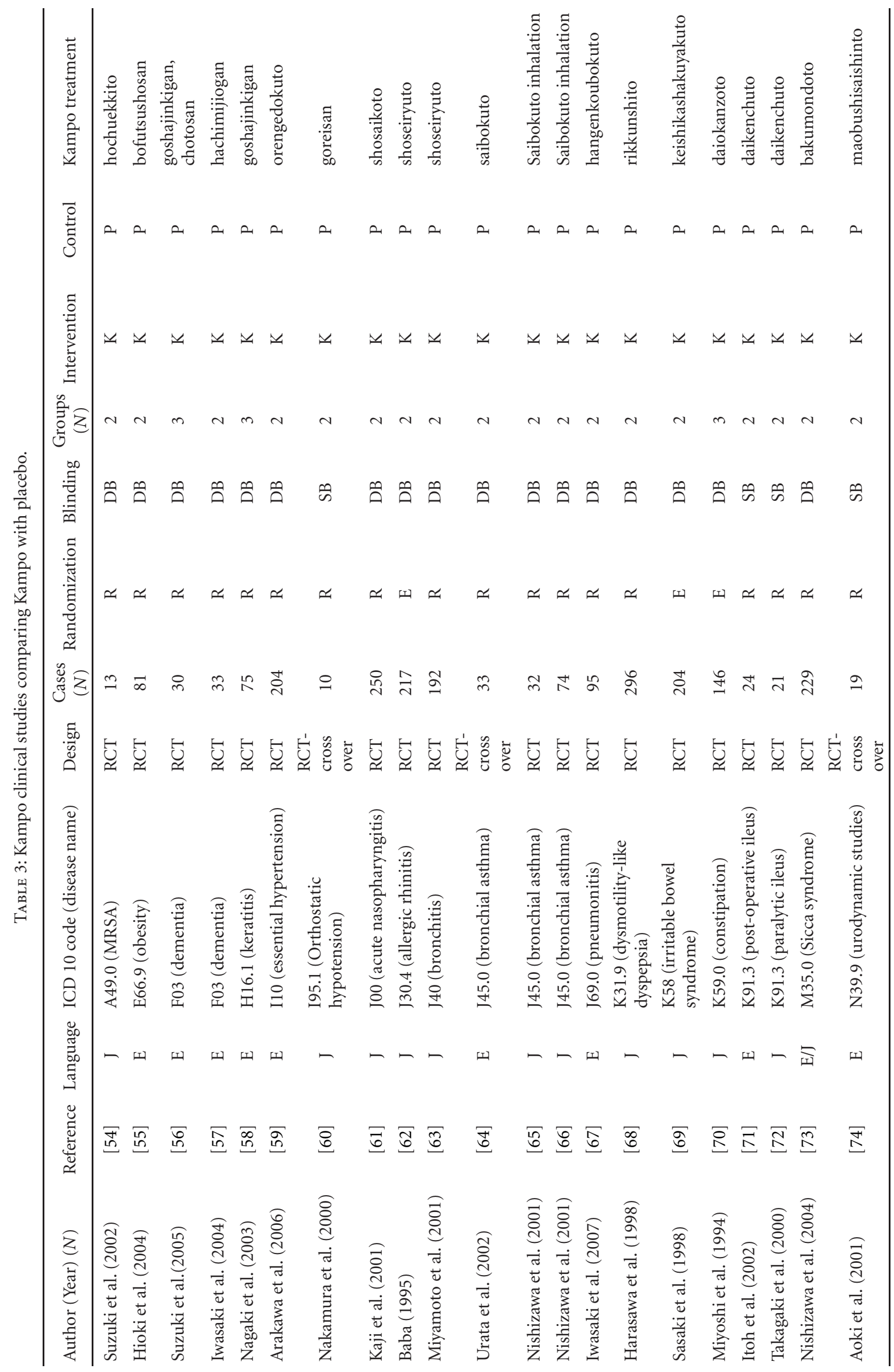




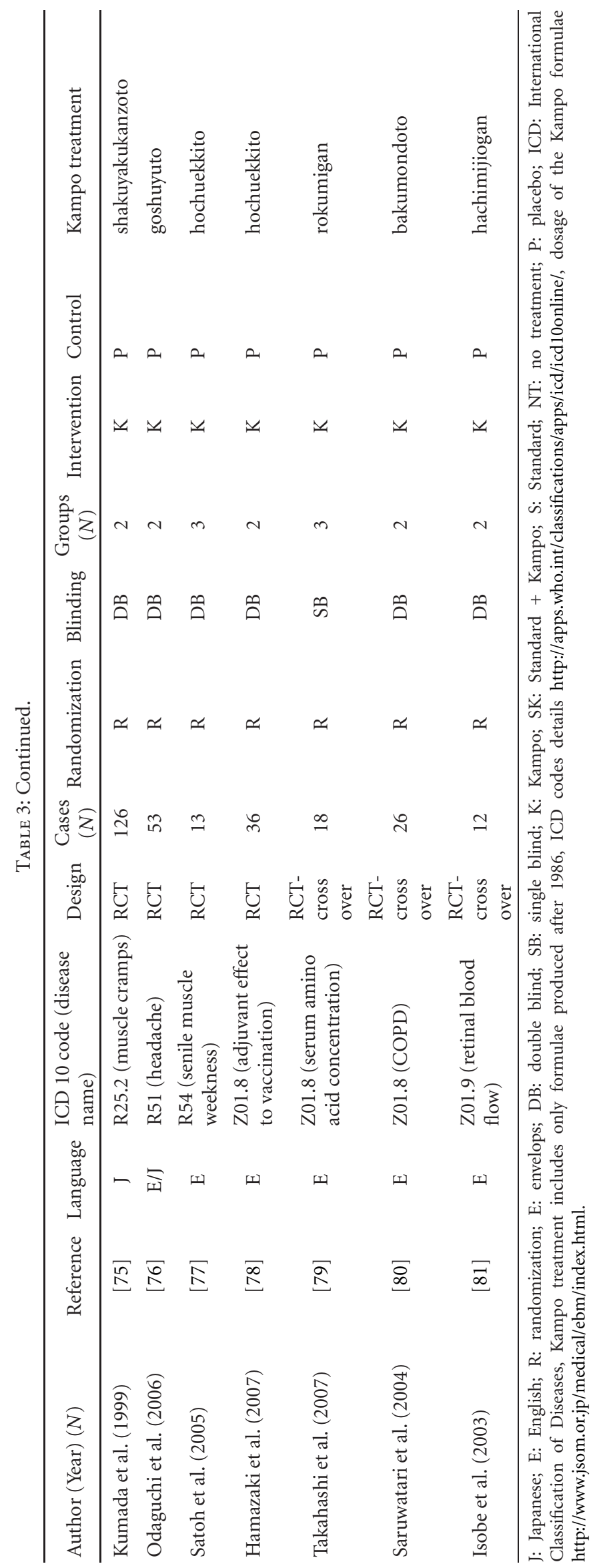




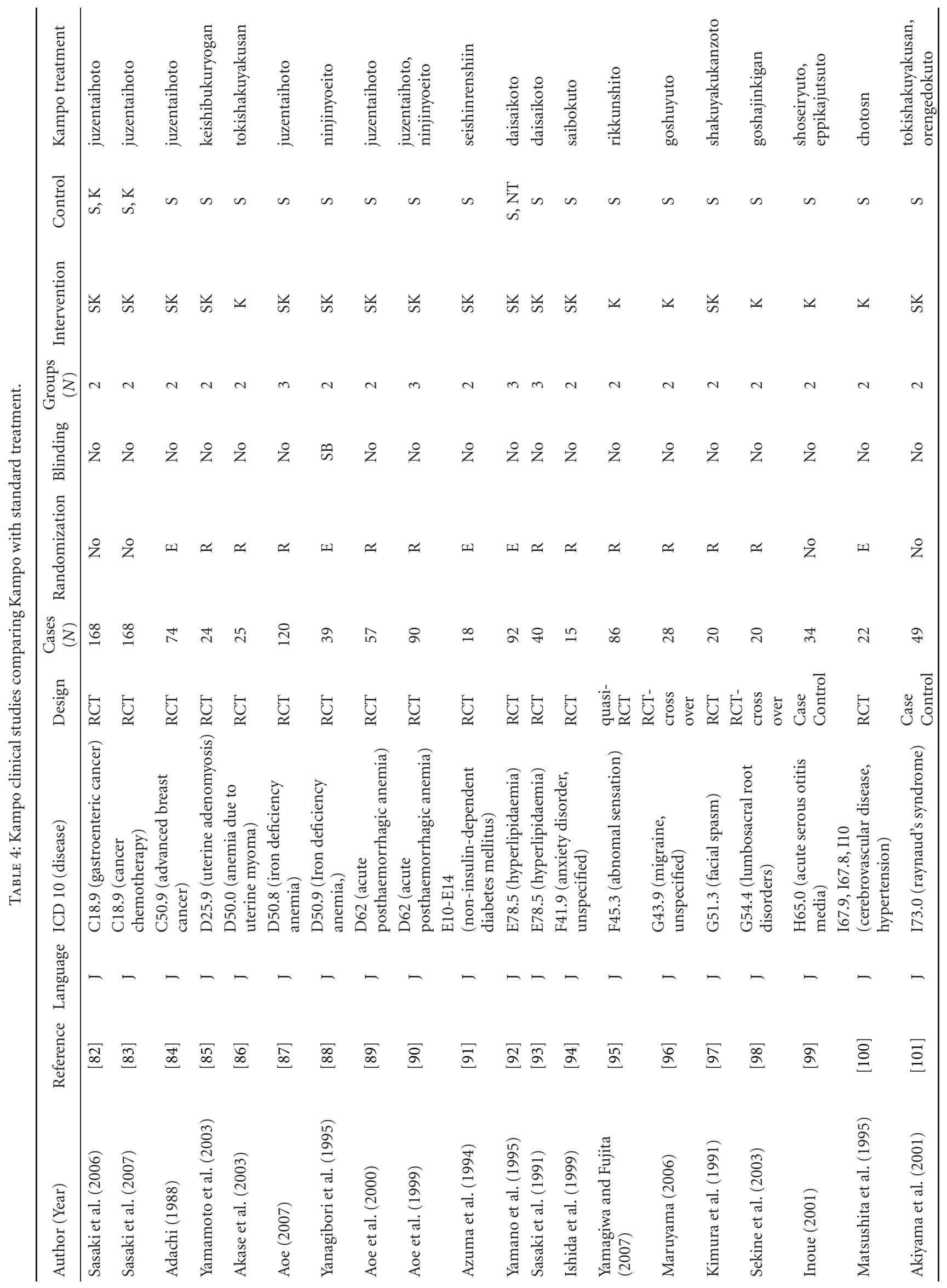




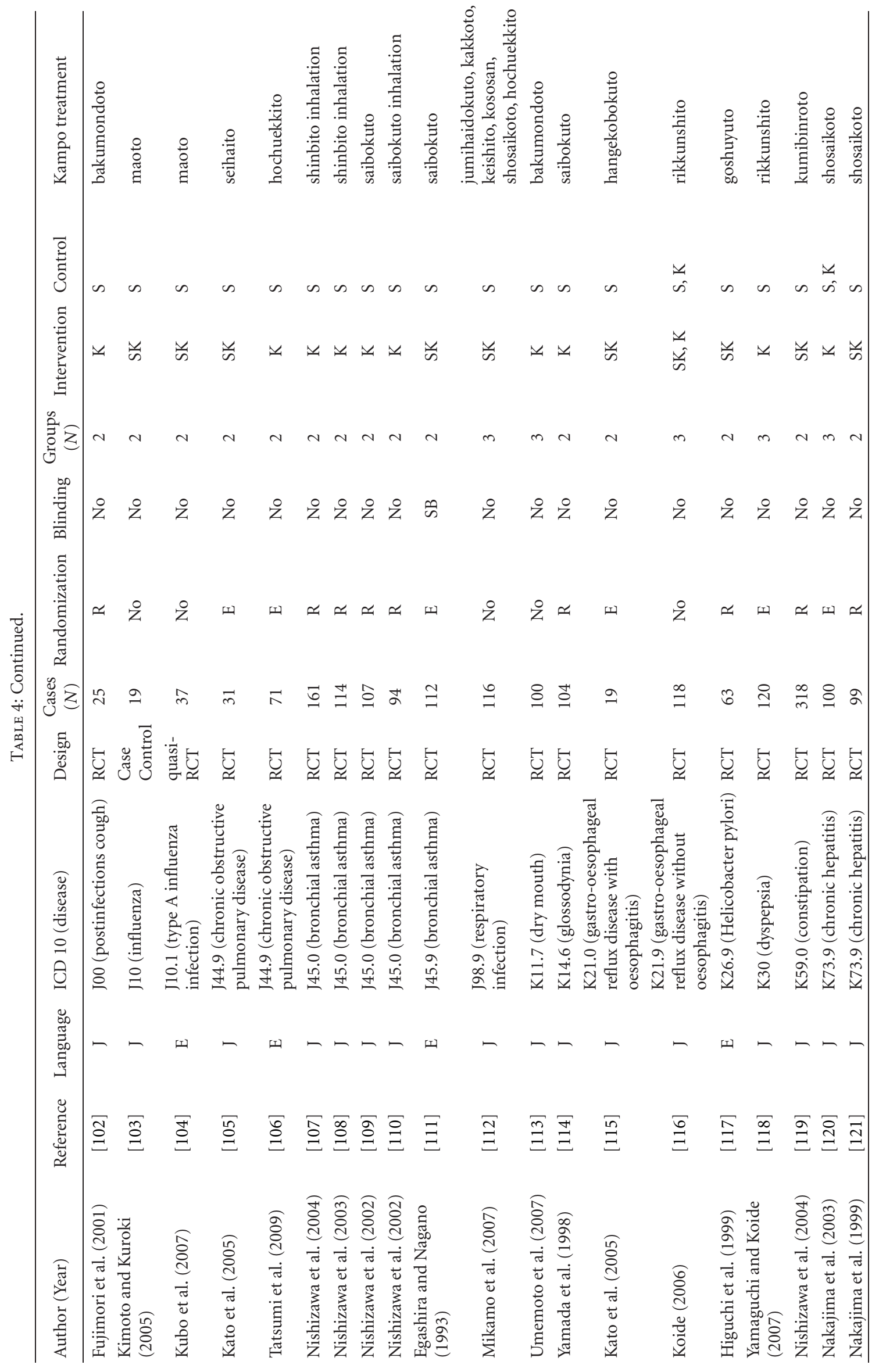




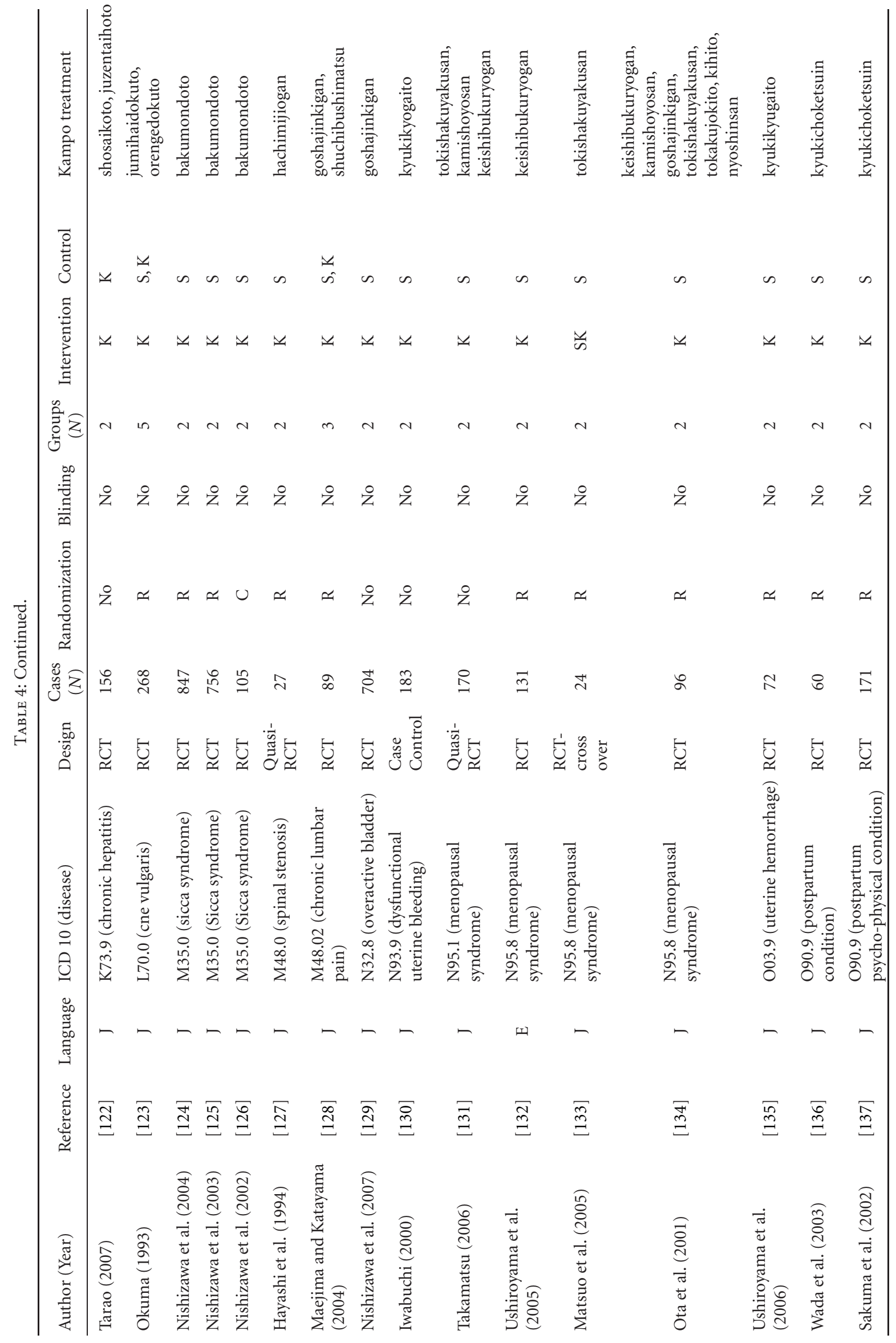




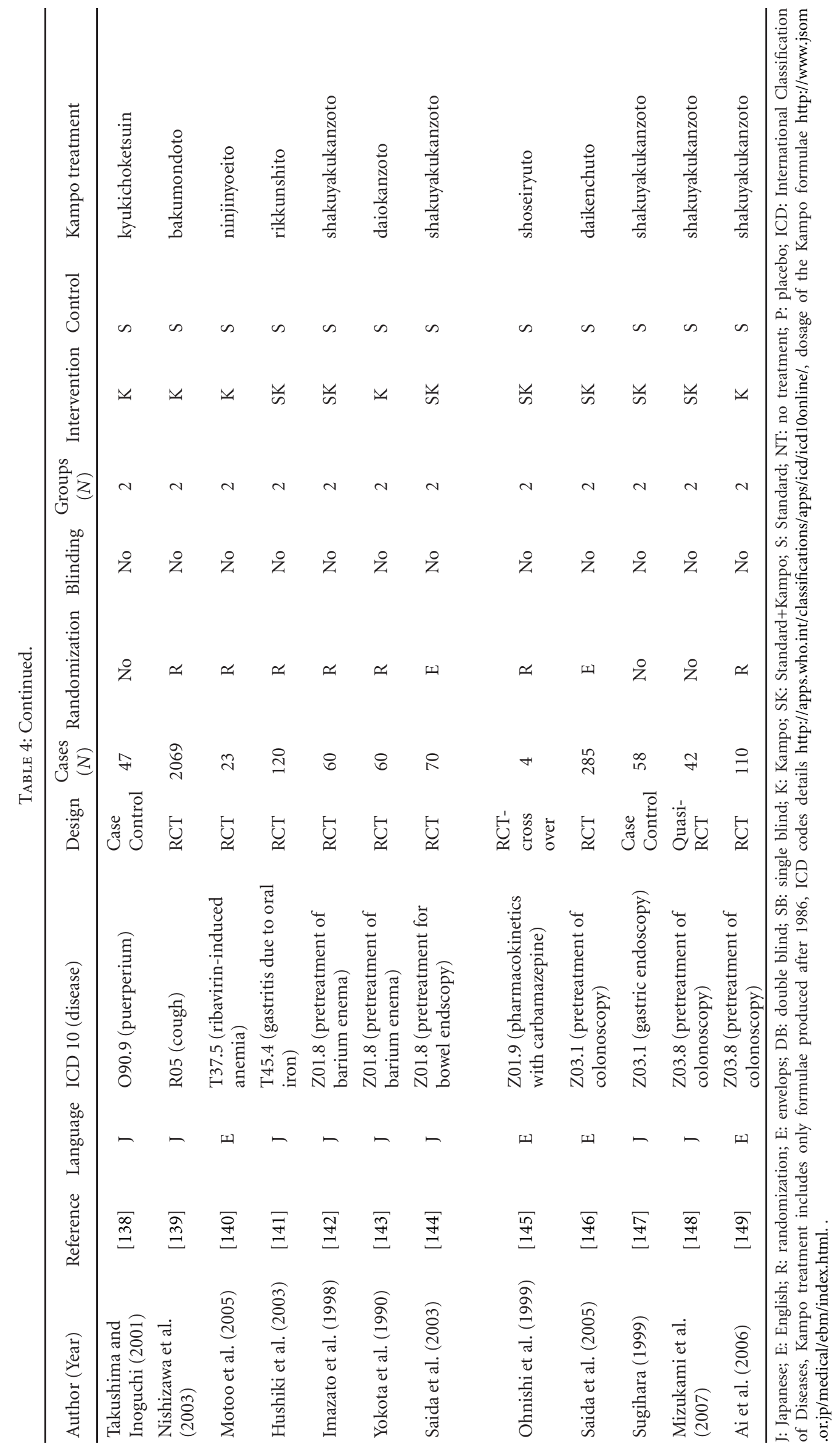


with a traditional approach, many research questions still need to be investigated. Kampo has been used for hundreds of years and is well integrated into the Japanese health care system, therefore it should be taken into account using an appropriate research strategy. When performing clinical research identical questions must be addressed for every new treatment, as well as for traditional treatments, which are already on the market:

(i) For whom and what is it used to treat?

(ii) Is it safe?

(iii) Is it superior to placebo?

(iv) Is it superior or equivalent to conventional standard treatment?

For traditional treatments, the order of research questions should differ from conventional drug research, because traditional treatments are already widely available [150]. First, knowledge is needed regarding who will benefit from the treatment and which diseases the treatment is intended to treat, as well as how it is to be administered. In addition, it would be helpful to get an idea as to whether the patients improve under the treatment not to mention the essential safety assessment.

All of these questions could be answered using a prospective observational study which evaluates these aspects in usual care. This has been done for other traditional treatments such as homeopathy [151-153], and is currently being carried out for Kampo at the Keio University [154]. This computer-based self-assessment system is divided into two domains. One is the patients' self-assessment at every visit using a visual analogue scale (VAS) and the other domain is an assessment by the physician. Data from both sources are combined and analyzed using data mining. The advantage of this system is that data is collected in a real-life setting. Also, Kampo values subjective complaints. This computer-based, self-assessment system, allows data incorporation of patient's subjective outcome measures.

Objective outcome measures which are often used in experimental RCTs are sometimes separated from subjective feelings. Kampo physicians value subjective complaints and diagnose sho not only based on objective findings, but also from the subjective complaints. The evaluation of the Kampo treatment by the physician is sometimes decided based on the subjective symptoms. Current Kampo clinical research has not taken this aspect into account. Due to the individualized treatment approach of Kampo, subjective outcome measures are relevant and should always be considered while planning a study. In addition to databases, some authors have also suggested that more individual single-case research including $N$ of one trials would be suitable to reflect Kampo medicine $[155,156]$. The main motivation to perform clinical research on traditional treatments is for justification purposes, most placebo-controlled trials on Kampo do not reflect the use of Kampo in usual practice and are therefore not helpful when making medical decisions in daily practice.
3.2. Testing for Superiority over Placebo. Previous research has followed the principles of conventional drug research by testing the superiority of a single Kampo formula over a placebo for a clearly defined conventional diagnosis. An RCT from 1998, for example, compared Rikkunshito with a kind of placebo (low dose of the same formula) for the treatment of dyspepsia [68]. Results from this kind of trial are helpful for the integration of a single formula into conventional care. A formula that has proven efficacy in a conventional drug trial could be used in the future without any Kampo knowledge. However, this provides no information about Kampo as a whole treatment system.

Nevertheless, this kind of research does not represent the traditional Kampo treatment. A traditional treatment is led from the Kampo diagnosis (by taking a patient history, abdominal examination, tongue and pulse diagnosis). If the aim of a clinical trial is to ask whether Kampo treatment in a traditional way is efficacious or not, the traditional treatment system has to be taken into account. For this purpose, an additional Kampo diagnosis with the conventional diagnosis could be used for choosing the appropriate Kampo medicine. There are two options; the first excludes the influences of the Kampo diagnostic procedure and the study could be performed in a similar way as suggested for the placebocontrolled study. When this design is used, the Kampo diagnosis is performed for all patients before randomization, although it is only needed for the group that actually receives Kampo.

The first design is that Kampo diagnoses and an appropriate treatment could be used for stratification within the randomization process (see Figure 1). This design is especially useful for pilot trials or smaller studies to prove Kampo as an individualized treatment system. This trial design allows for an individual Kampo treatment according to the Kampo diagnosis. However, it also means that a range of different formulae will be administered. In order to ensure blinding, it might be necessary to prepare an adequate placebo for each formula, if they differ in appearance, smell and taste. In this type of trial, the patients should not only be blinded for the treatment, but they should also not receive any information about their Kampo diagnosis. Designs like this have already been used for homeopathy [157].

For many Western diagnoses, more than two Kampo diagnoses are common. Different patterns would result in a larger number of subgroups and some of these might be too small to have enough statistical power for subgroup analysis. For this reason, it makes sense to use the pooled patterns for primary analysis and to pre-specify subgroup analysis for the more common patterns. Another possibility, which might be easier to handle for the trial process, is to use the Kampo diagnosis as additional inclusion criteria and to recruit only those patients with relevant Kampo diagnosis for the formula under research. An example for this can be seen in the study by Kobayashi [158]. When using this design, it must be recognized that a large number of patients may need to be screened. In addition, the results are less representative for the Western diagnosis and integration into conventional care might be more difficult, because Western 


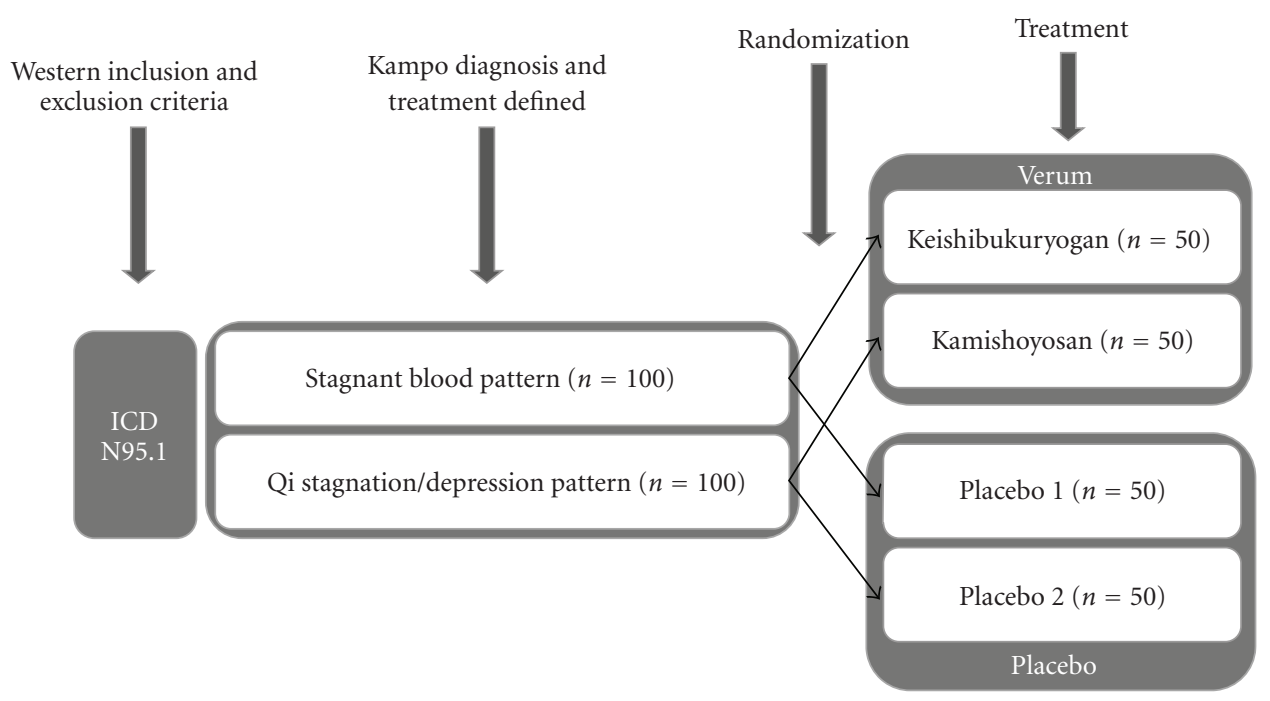

Figure 1: Combining the Western and Kampo diagnosis for a placebo-controlled trial: to evaluate the efficacy of Kampo drug treatment, for example, for menopausal symptoms (ICD N95.1).

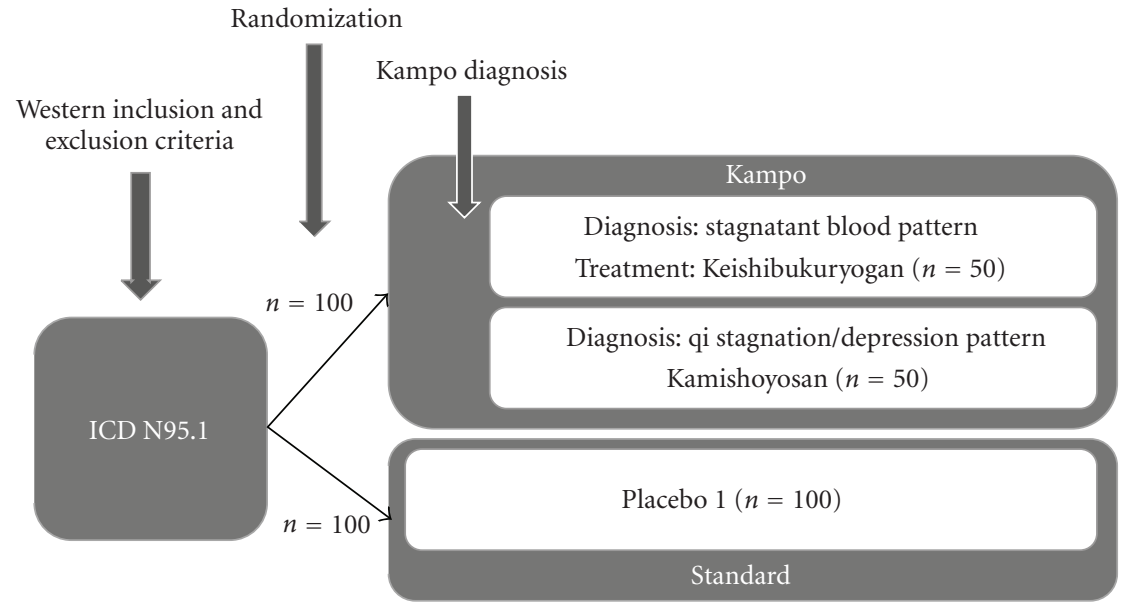

Figure 2: Combining the Western and Kampo diagnosis for a standard care controlled trial: to evaluate the effectiveness of Kampo as a whole treatment system, for example, for menopausal symptoms (ICD N95.1).

trained doctors could not differentiate between the different Kampo diagnoses.

\subsection{Testing for Non-Inferiority or Superiority over Standard} Care. Doctors and patients want to know whether it is better to use Kampo instead of, or in addition to conventional treatment. Depending on its causality or external validity, the main focus of these studies could be performed more experimentally (homogenous patients and clearly defined treatment protocols) or more pragmatically (heterogeneous patients and a treatment which represents usual care) [159]. Especially for chronic diseases where a more complex treatment is needed [160], a pragmatic study design to test Kampo as an additional treatment could provide useful information for decision making. Similarly for the suggested placebo-controlled study designs, it is possible to use an individualized Kampo treatment within these studies.
The second possibility is to see the diagnostic procedure as part of the Kampo treatment, and the diagnostic procedure be used only on the Kampo group after randomization Figure 2. Study designs shown in Figures 1 and 2 are used to answer different research questions. The first option focuses on the treatment effects of the drug, whereas the second option provides a broader picture and evaluates Kampo as a whole treatment system, which consists of both the diagnostic procedure and the drug treatment.

3.4. Taking Patient Expectations into Account. Patient preferences and patient expectation can play a role in complementary and alternative medicine trials. Two systematic reviews suggest that the influence of patient expectations on outcomes is related to both within-group changes and between-group differences [161, 162]. This has already been shown for acupuncture [163]. If the patients in a Kampo 
trial have higher expectations of a positive outcome than the "average" patient, then this could result in withingroup changes that are larger than in a more representative sample. High expectations might also be associated with high response rates and improved outcomes in the placebocontrolled group. This could result in a ceiling effect making it more difficult to detect a significant difference between verum and placebo. Different strategies are available to deal with this problem, such as: including a run-in phase, stratification for randomization and measuring expectation. A simple tool for measuring aspects of expectations at baseline is to ask questions such as: "How effective do you expect the treatment to be?" with responses such as "very effective", "effective", "slightly effective", "not effective" or "don't know". These data could be used to make adjustments in the primary data analysis.

\section{Conclusion}

Kampo is a holistic and individualized treatment with a long tradition and future research is required to take this into account. RCT is the appropriate study design for testing efficacy or effectiveness, however within such a study, the treatment should be individualized according to the Kampo diagnosis.

\section{Funding}

This work was supported by Grant-in-Aide for Research on Applied Use of Statistics and Information, Health and Labour Sciences Research and Clinical Research for Development of Preventive Medicine and New Therapeutics from Ministry of Health, Labour and Welfare of Japan. This work was also supported by the Center for Clinical Trials, Japan Medical Association. Claudia Witts' Chair for Complementary Medicine is endowed by the CarstensFoundation. Research grant for doctoral candidates from the German Academic Exchange Service (DAAD) to L. H.

\section{References}

[1] K Terasawa, "Evidence-based reconstruction of Kampo medicine: part I-is Kampo CAM?" Evidence-Based Complementary and Alternative Medicine, vol. 1, pp. 11-16, 2004.

[2] Y. Fujikawa, Nihon Igakushi (History of Japanese Medicine), Nagayama Shoten, Tokyo, Japan, 1979.

[3] Y. Otsuka, Pharmacotherapy in Oriental Medicine, Excerpta Medica, Tokyo, Japan, 1988.

[4] S. Sakai, Nihon Iryoshi (History of Medical Care in Japan), Tokyo Shoseki, Tokyo, Japan, 1982.

[5] H. Reissenweber, "Japanische Phytotherapie (Kampo) und ihr Stellenwert in der modernen Medizin," Zeitschrift für Phytotherapie, vol. 23, pp. 242-246, 2002 (German).

[6] A. Ishibashi, H. Kosoto, S. Ohno et al., "General introduction to Kampo," in Introduction to Kampo, Japanese Traditional Medicine, The Japan Society for Oriental Medicine, Ed., pp. 2-13, Elsevier, Tokyo, Japan, 2005.

[7] Nikkei Medical Group, "Utilization survey of Kampo medicines," vol. 10, supplement, pp. 41-47, 2007.
[8] K Terasawa, "Evidence-based reconstruction of Kampo medicine: part II-the concept of Sho," Evidence-Based Complementary and Alternative Medicine, vol. 1, pp. 119-123, 2004.

[9] S.-H. Choi and I.-M. Chang, "A milestone in codifying the wisdom of traditional Oriental medicine: TCM, Kampo, TKM, TVM-WHO international standard terminologies on traditional medicine in the West Pacific Region," EvidenceBased Complementary and Alternative Medicine, 2009.

[10] K. Watanabe, S. Ishino, and T. Sakiyama, "Kampo Sho codes," Assiste Japan, Tokyo, Japan, 2009.

[11] "Evidence Report of Kampo Treatment by Japan Society for Oriental Medicine,” June 2009, http://www.jsom.or.jp/ medical/ebm/ere/index.html .

[12] "The Cochrane Central Register of Controlled Trials (CENTRAL)," June 2009, http://www.cochranejournalclub.com/ .

[13] ICHUSHI (Japan Medical Abstracts Society), June 2009, http://www.jamas.or.jp/ .

[14] “Japan Kampo Medicines Manufacturers Association," June 2009, http://www.nikkankyo.org/topix/grant.html .

[15] PubMed, June 2009, http://www.ncbi.nlm.nih.gov/PubMed .

[16] T. Seki, T. Matsumoto, H. Deguchi, Y. Satoh, and K. Ikeuchi, "Evaluation of the efficacy of hochuekkito in preventing MRSA colonization and infection," Kampo Igaku, vol. 23, pp. 196-197, 1999 (Japanese).

[17] H. Konno, Y. Maruo, S. Baba et al., "Improvement of Host Immunity by Juzen-taiho-to in the postoperative adjuvant chemotherapy for patients with gastric cancer," Biotherapy, vol. 11, pp. 193-199, 1997 (Japanese).

[18] S. Saito, H. Iwagaki, N. Kobayashi et al., "Effects of a Japanese herbal medicine (TJ-41) on surgical stress of patients with gastric and colorectal cancer," Nihon RInsho Geka Gakki Zashi, vol. 67, pp. 568-574, 2006 (Japanese).

[19] S. Suzuki, R. Abe, T. Nomizu et al., "Effect of juzentaihoto (TJ-48) on leukopenia in patients receiving cancer chemotherapy," Progress in Medicine, vol. 15, pp. 1968-1971, 1995 (Japanese).

[20] K. Higuchi, Y. Shimizu, T. Yasumura et al., "Preventive effect of liver carcinogenesis by Juzen-Taiho-To in the patients with liver cirrhosis," Kan-Tan-Sui, vol. 44, pp. 341-346, 2002 (Japanese).

[21] T. Ushiroyama, A. Ikeda, M. Sakai et al., "Effects of unkei-to, an herbal medicine, on endocrine function and ovulation in women with high basal levels of luteinizing hormone secretion," Journal of Reproductive Medicine for the Obstetrician and Gynecologist, vol. 46, no. 5, pp. 451-456, 2001.

[22] T. Ushiroyama, T. Hosotani, K. Mori, Y. Yamashita, A. Ikeda, and M. Ueki, "Effects of switching to wen-jing-tang (unkeito) from preceding herbal preparations selected by eightprinciple pattern identification on endocrinological status and ovulatory induction in women with polycystic ovary syndrome," The American Journal of Chinese Medicine, vol. 34, pp. 177-187, 2006.

[23] T. Ushiroyama, A. Ikeda, S. Higashio et al., "Unkei-to for correcting luteal phase defects," Journal of Reproductive Medicine for the Obstetrician and Gynecologist, vol. 48, no. 9, pp. 729-734, 2003.

[24] T. Namiki, "Basic and clinical investigation of the effect of Kampo medicine on arteriosclerosis," Uehara Kinen Seimei Kagaku Zaidan Kenkyu Hokokushu, vol. 21, pp. 60-63, 2007 (Japanese). 
[25] K. Iwasaki, T. Satoh-Nakagawa, M. Maruyama et al., "A randomized, observer-blind, controlled trial of the traditional Chinese medicine Yi-Gan San for improvement of behavioral and psychological symptoms and activities of daily living in dementia patients," Journal of Clinical Psychiatry, vol. 66, pp. 248-252, 2005.

[26] R. Aizawa, T. Kanbayashi, Y. Saito et al., "Effects of Yoku-kansan-ka-chimpi-hange on the sleep of normal healthy adult subjects," Psychiatry and Clinical Neurosciences, vol. 56, no. 3, pp. 303-304, 2002.

[27] K. Higashi, H. Rakugi, and H. Yu, "Effect of kihito extract granules on cognitive function in patients with Alzheimer'stype dementia," Geriatrics \& Gerontology International, vol. 7, pp. 245-251, 2007.

[28] N. Ikeda, S. Hayasaka, Y. Nagaki, Y. Hayasaka, C. Kadoi, and M. Matsumoto, "Effects of Kakkon-to and Sairei-to on aqueous flare elevation after complicated cataract surgery," The American Journal of Chinese Medicine, vol. 30, pp. 347$353,2002$.

[29] N. Ikeda, S. Hayasaka, Y. Nagaki, Y. Hayasaka, C. Kadoi, and M. Matsumoto, "Effects of traditional Sino-Japanese herbal medicines on aqueous flare elevation after smallincision cataract surgery," Journal of Ocular Pharmacology and Therapeutics, vol. 17, no. 1, pp. 59-65, 2001.

[30] Y. Abe, "The efficacy of goshajinkigan against lymphedema," Kampo Igaku, vol. 25, pp. 284-287, 2002 (Japanese).

[31] T. Yoshimoto, H. Mori, H. Kurata, Y. Shimazaki, and A. Ikegawa, "Comparative study of Kampo preparations ShoSei-Ryu-To and Maoh-Bushi-Saisin-To for nasal allergy and allergic conjunctivitis in Spring," Therapeutic Research, vol. 23, pp. 2253-2259, 2002 (Japanese).

[32] H. Mori, H. Kurata, Y. Shimazaki, and T. Yoshimoto, "Comparative study of Kampo preparations Sho-Sei-RyuTo and Kei-Ma-Kakuhan-To for nasal allergy and allergic conjunctivitis in Spring," Therapeutic Research, vol. 20, pp. 2941-2947, 1999 (Japanese).

[33] Y. Nishizawa, Y. Nishizawa, F. Yoshioka et al., "Clinical Effect of a Kampo medicine, Chai-po-tang (Japanese name: Saiboku-to) compared with Xiao-quing-long-tang (Japanese name: Shoseiryu-to) in asthmatics with anxiety and depression due to asthmatic attacks," Nihon Toyo Shinshin Igaku Kenkyu, vol. 18, pp. 11-17, 2003 (Japanese).

[34] S. Mizuno, K. Yamagiwa, M. Iwata et al., "Effect of early treatment with TSUMURAR Rikkunshito on gastrointestinal symptoms after resection of gastric cancer-focusing on reflux esophagitis," Progress in Medicine, vol. 21, pp. 1366 1367, 2001 (Japanese).

[35] T. Nishida, "Effect of rikkunshito on gastrointestinal function in patients after gastrectomy," Progress in Medicine, vol. 26, pp. 3224-3225, 2006 (Japanese).

[36] H. Oyabu, S. Matsuda, S. Kurisu et al., "Evaluation of daikenchuto for adhesive ileus in randomized trial," Progress in Medicine, vol. 15, pp. 1954-1958, 1995 (Japanese).

[37] K. Mori, T. Kondo, Y. Kamiyama, Y. Kano, and K. Tominaga, "Preventive effect of Kampo medicine (Hangeshashin-to) against irinotecan-induced diarrhea in advanced non-smallcell lung cancer," Cancer Chemotherapy \& Pharmacology, vol. 51, pp. 403-406, 2003.

[38] T. Okabayashi, N. Tanaka, and K. Orita, "The effect of Kanpo medicine, Inchinko-to for the bilirubin reduction rate after biliary drainage on the patients with obstructive jaundice," Nihon Rinsho Geka Gakkaishi, vol. 59, pp. 2495-2500, 1998 (Japanese).
[39] S. Endo, T. Nishida, K. Nishikawa et al., "Dai-kenchuto, a Chinese herbal medicine, improves stasis of patients with total gastrectomy and jejunal pouch interposition," American Journal of Surgery, vol. 192, no. 1, pp. 9-13, 2006.

[40] S. Ohno, "The effect of Kampo medicine on salivary secretion in Sjogren's syndrome," Kampo to Saishin-Chiryu, vol. 15, pp. 134-140, 2006 (Japanese).

[41] S. Maejima and Y. Katayama, "Spine and spinal cord diseases 1. Traditional Chinese medicines for the spinal disorders," Kampo to Saishin-Chiryo, vol. 13, pp. 232-236, 2004 (Japanese).

[42] N. Yoshikawa, H. Ito, T. Sakai et al., "A prospective controlled study of Sairei-to in childhood IgA nephropathy with focal/minimal mesangial proliferation," Japanese Journal of Nephrology, vol. 39, pp. 503-506, 1997 (Japanese).

[43] N. Yoshikawa, H. Ito, Y. Takekoshi et al., "Standard versus long-term prednisolone with Sairei-to for initial therapy in childhood steroid-responsive nephrotic syndrome: a prospective controlled study," Japanese Journal of Nephrology, vol. 40, pp. 587-590, 1998 (Japanese).

[44] K. Oribe and Y. Nishida, "Efficacy of hachimijiogan for discomfort after surgery for uterine prolapse," Gekkan Kampo Ryoho, vol. 10, pp. 282-288, 2006 (Japanese).

[45] K. Takamatsu, C. Musha, H. Okana, N. Higashidate, and H. Otha, "Study of usefulness of Kampo therapy for climacteric disorders," Sanfujinka Kampo Kenkyu no Ayumi, vol. 19, pp. 111-116, 2002 (Japanese).

[46] S. Kawakami, J. Nishimura, M. Umeki et al., "Kampo therapy for feeling of lactation deficiency," Sanfujinka Kampo Kenkyu no Ayumi, vol. 20, pp. 140-143, 2003 (Japanese).

[47] T. Ushiroyama, K. Sakuma, and M. Ueki, "Efficacy of the kampo medicine Xiong-gui-tiao-xue-yin (Kyuki-chouketsuin), a traditional herbal medicine, in the treatment of maternity blues syndrome in the postpartum period," The American Journal of Chinese Medicine, vol. 33, pp. 117-126, 2005.

[48] M. Yoshida, "Efficacy of goreisan suppository for vomiting in young children," Toyoigaku, vol. 28, pp. 36-38, 2000 (Japanese).

[49] Y. Nishizawa, Y. Nishizawa, Y. Amenomori et al., "A randomized paralleled group comparison in multicenter cooperation: analgesic effect and safety with Gosha-jjinkigan and Shakuyaku-kanzo-to in the treatment of painful muscle cramps in patients with cirrhosis," Itami to Kampo, vol. 10, pp. 13-18, 2000 (Japanese).

[50] H. Yoshikawa, T. Ikeuchi, and Y. Kai, "Clinical effects of Kyuki-kyogai-to and Sairei-to for essential microscopic hematuria," Kampo to Saishin-Chiryo, vol. 6, pp. 55-58, 1997 (Japanese).

[51] Y. Kishida, H. Miki, and T. Nishii, "Therapeutic effects of Saireto (TJ-114), a traditional Japanese herbal medicine, on postoperative edema and inflammation after total hiparthroplasty," Phytomedicine, vol. 14, pp. 581-586, 2007.

[52] K. Hasegawa, Y. Mizutani, H. Kuramoto et al., "The effect of L-glutamine and Shakuyaku-Kanzo-to for paclitaxel-induced myalgia/arthralgia," Gan to Kagaku Ryoho, vol. 29, pp. 569574, 2002 (Japanese).

[53] T. Ueda, K. Yamashita, Y. Nakamori, T. Shimazu, and Y. Sugimoto, "Study of the MRSA carriage-preventing effect of L-hochuekkito (TJ-41): 1st report," Progress in Medicine, vol. 19, pp. 1000-1003, 1999 (Japanese). 
[54] J. Suzuki, S. Arata, and M. Sugiyama, "Improvement of immunity and nutrition by hochuekkito in immunocompromised hosts for the control of MRSA," Progress in Medicine, vol. 22, pp. 1362-1363, 2002 (Japanese).

[55] C. Hioki, K. Yoshimoto, and T. Yoshida, "Efficacy of bofutsusho-san, an oriental herbal medicine, in obese Japanese women with impaired glucose tolerance," Clinical and Experimental Pharmacology and Physiology, vol. 31, no. 9, pp. 614619, 2004.

[56] T. Suzuki, S. Futami, Y. Igari et al., "A Chinese herbal medicine, choto-san, improves cognitive function and activities of daily living of patients with dementia: a doubleblind, randomized, placebo-controlled study," Journal of the American Geriatrics Society, vol. 53, no. 12, pp. 2238-2240, 2005.

[57] K. Iwasaki, S. Kobayashi, Y. Chimura et al., "A randomized, double-blind, placebo-controlled clinical trial of the Chinese herbal medicine "ba wei di huang wan" in the treatment of dementia," Journal of the American Geriatrics Society, vol. 52, no. 9, pp. 1518-1521, 2004.

[58] Y. Nagaki, S. Hayasaka, Y. Hayasaka et al., "Effects of Goshajinkigan on corneal sensitivity, superficial punctate keratopathy and tear secretion in patients with insulindependent diabetes mellitus," American Journal of Chinese Medicine, vol. 31, no. 1, pp. 103-109, 2003.

[59] K. Arakawa, K. Saruta, K. Abe et al., "Improvement of accessory symptoms of hypertension by TSUMURA Oregedokuto extract, a four herbal drugs containing Kampo-Medicine Granules for ethical use: a double-blind, placebo-controlled study," Phytomedicine, vol. 13, pp. 1-10, 2006.

[60] H. Nakamura, T. Nakamura, S. Nakagawa, and Y. Aizawa, "Efficacy of goreisan in treatment of orthostatic hypotension in patients with diabetes mellitus," Diabetes Frontier, vol. 11, pp. 561-563, 2000 (Japanese).

[61] M. Kaji, S. Kashiwagi, M. Yamakido, H. Hiraga, Y. Honma, and T. Hurukawa, "A double-blind, placebo-controlled study of TSUMURA Shosaikoto (TJ-19) for common cold," Rinsho to Kenkyu, vol. 78, pp. 2252-2268, 2001 (Japanese).

[62] S. Baba, "Double-blind Clinical Trial of Sho-seiryu-to (TJ19) for perennial nasal allergy," Jibiinkoka Rinsho, vol. 88, pp. 389-405, 1995 (Japanese).

[63] T. Miyamoto, H. Inoue, S. Kitamura et al., "Effect of TSUMURA Sho-seiryu-to (TJ-19) on bronchitis in a doubleblind placebo-controlled study," Rinsho Iyaku, vol. 17, pp. 1189-1214, 2001 (Japanese).

[64] Y. Urata, S. Yoshida, Y. Irie et al., "Treatment of asthma patients with herbal medicine TJ-96: a randomized controlled trial," Respiratory Medicine, vol. 96, no. 6, pp. 469474, 2002.

[65] Y. Nishizawa, Y. Nishizawa, F. Yoshioka et al., "Suppressive effect of Kampo medicine, Cai-pu-tang (Japanese name: Saiboku-to, TJ-96) on bronchospasms in aspirin-induced bronchial asthmatic patients and decrease of chronic pain, especially psychological pain," Itami to Kampo, vol. 11, pp. 14-21, 2001 (Japanese).

[66] Y. Nishizawa, Y. Nishizawa, F. Yoshioka, F. Nagano, and H. Gracy-Goto, "Suppressive effect of Japanese herbal medicine, Saiboku-to (Chai-Pu-Tang) on bronchospasms in aspirininduced bronchial asthmatic patients a randomized, doubleblind test," Jibi-inkoka Tenbo, vol. 44, pp. 5-13, 2001 (Japanese).

[67] K. Iwasaki, S. Kato, Y. Monma et al., "A pilot study of Banxia Houpu Tang, a traditional Chinese medicine, for reducing pneumonia risk in older adults with dementia," Journal of the American Geriatrics Society, vol. 55, no. 12, pp. 2035-2040, 2007.

[68] S. Harasawa, A. Miyoshi, T. Miwa et al., "Double-blind multicenter post-marketing clinical trial of TJ-43 TSUMURA Rikkunshi-to for the treatment of dysmotility-like dyspepsia," Igaku no Ayumi, vol. 187, pp. 207-229, 1998 (Japanese).

[69] D. Sasaki, S. Uehara, N. Hiwata et al., "Clinical efficacy of keishikashakuyakuto for irritable bowel syndrome-a multicenter, randomized, parallel-group clinical trial," Rinsho to Kenkyu, vol. 75, pp. 1136-1152, 1998 (Japanese).

[70] A. Miyoshi, O. Masamune, H. Fukotomi et al., "The clinical effect of TSUMURA Daio-Kanzo-To extract granules for ethical use (TJ-84) on constipation using double blind test," Shokakika, vol. 18, pp. 299-312, 1994 (Japanese).

[71] T. Itoh, J. Yamakawa, M. Mai, N. Yamaguchi, and T. Kanda, "The effect of the herbal medicine dai-kenchu-to on postoperative ileus," Journal of International Medical Research, vol. 30, no. 4, pp. 428-432, 2002.

[72] Y. Takagaki, S. Kawasaki, H. Komai, K. Fujiwara, and Y. Naito, "The effect of Chinese herb medicine (Dai-Kenchu-to) on paralytic ileus after repair of abdominal aortic aneurysm," Nihon Rinsho Geka Gakkai Zasshi, vol. 61, pp. 325-328, 2000 (Japanese).

[73] Y. Nishizawa, Y. Nishizawa, F. Yoshioka et al., "Long-term effect of traditional Chinese herbal medicine. Mai-MenDong-Tang ( = Bakumondo-to) on sicca syndrome, especially, salivary secretion in patients with primary Sjogrens's syndrome: a multicenter, randomised well controlled groupparallel double-blind study," Nihon Daekisen Gkkaishi, vol. 45, pp. 66-74, 2004 (Japanese).

[74] Y. Aoki, K. Ueda, K. Tsutani, and K. Kohri, "The influence of formula Ma-Huang-Fu-Zi-Xi-Xin-Tang (Mao-bushisaishin-to;Mbst) on the results of urodynamic studies," Journal of Traditional Medicines, vol. 18, pp. 203-209, 2001.

[75] T. Kumuda, H. Kumada, M. Yoshida, S. Nakano, H. Suzuki, and T. Tango, "Effects of Shakuyaku-kanzo-to (Tsumura TJ68) on muscle cramps accompanying cirrhosis in a placebocontrolled double-blind parallel study," Rinsho Iyaku, vol. 15, pp. 499-523, 1999 (Japanese).

[76] H. Odaguchi, A. Wakasugi, H. Ito et al., "The efficacy of goshuyuto, a typical Kampo (Japanese herbal medicine) formula, in preventing episodes of headache," Current Medical Research and Opinion, vol. 22, no. 8, pp. 1587-1597, 2006.

[77] N. Satoh, S. Sakai, T. Kogure et al., "A randomized double blind placebo-controlled clinical trial of Hochuekkito, a traditional herbal medicine, in the treatment of elderly patients with weakness $\mathrm{N}$ of one and responder restricted design," Phytomedicine, vol. 12, pp. 549-554, 2005.

[78] K. Hamazaki, S. Sawazaki, M. Itomura et al., "No effect of a traditional Chinese medicine, Hochu-ekki-to, on antibody titer after influenza vaccination in man: a randomized, placebo-controlled, double-blind trial," Phytomedicine, vol. 14, pp. 11-14, 2007.

[79] H. Takahashi, R. Nakao, K. Hirasaka, K. Kishi, and T. Nikawa, "Effects of single administration of Rokumi-gan (TJ-87) on serum amino acid concentration of 6 healthy Japanese male volunteers," Journal of Investigative Medicine, vol. 54, pp. 9198, 2007.

[80] J. Saruwatari, S. Hisaeda, Y. Higa, Y. Tomiyasu, K. Nakagawa, and T. Ishizaki, "The in-vivo effect of bakumondo-to (TJ29), a traditional Japanese medicine used for treatment of 
chronic airway disease, on cytochrome P450 1A2, xanthine oxidase and $\mathrm{N}$-acetyltransferase 2 activity in man," Journal of Pharmacy and Pharmacology, vol. 56, pp. 1171-1177, 2004.

[81] H. Isobe, K. Yamamoto, and J.-C. Cyong, "Effects of Hachimi-jio-gan (Ba-wei-di-huang-wan) on blood flow in the human central retinal artery," American Journal of Chinese Medicine, vol. 31, no. 3, pp. 425-435, 2003.

[82] K. Sasaki, E. Ezoe, J. Araya, H. Takasaka, T. Furuhata, and K. Hirata, "Effects of Kampo medicine on the immune function in gastroenteric cancer patients," Kampo to Saishin-Chiryo, vol. 15, pp. 9-14, 2006 (Japanese).

[83] K. Sasaki, H. Takasaka, T. Furuhata, and K. Hirata, "Effect of Kampo medicine on cancer chemotherapy," Geka Chiryo, vol. 97, pp. 504-510, 2007 (Japanese).

[84] I. Adachi, "Effects of oriental medical drugs for patients with advanced breast cancer," Pharmaceutical Medicine, vol. 6, pp. 46-50, 1988 (Japanese).

[85] K. Yamamoto, H. Hirano, N. Ikoma, T. Maekura, Y. Sekiguchi, and N. Ohtani, "Efficacy of keishibukuryogan for hysteromyoma/uterine adenomyosis," Sanfujinka Kampo Kenkyu no Ayumi, vol. 20, pp. 135-137, 2003 (Japanese).

[86] T. Akase, T. Akase, S. Onodera et al., "A comparative study of the usefulness of toki-shakuyaku-san and an oral iron preparation in the treatment of hypochromic anemia in cases of uterine myoma," Yakugaku Zasshi, vol. 123, pp. 817-824, 2003 (Japanese).

[87] H. Aoe, "Effect of Juzen-taiho-to on haematological recovery from predeposit autologous blood donation," Pharmaceutical Medicine, vol. 25, pp. 11-14, 2007 (Japanese).

[88] A. Yanagibori, M. Miyagi, Hori Masayuki, K. Otaka, H. Matsushima, and M. Ito, "Effect of ninjineiyoto on iron deficiency anemia," Rinsho to Kenkyu, vol. 72, pp. 2605-2608, 1995 (Japanese).

[89] H. Aoe, T. Matsuo, M. Ebisutani et al., "Effects of juzentaihoto (ten strong tonic herbs decoction) on presurgical autologous blood pooling in cancer patients," Sanfujinka Kampo Kenkyu no Ayumi, vol. 17, pp. 67-71, 2000 (Japanese).

[90] H. Aoe, Y. Sumida, N. Kawahara, A. Kotaka, K. Shigeta, and N. Akamatsu, "Efficacy of an erythropoietin preparation and Kampo medicines in preoperative autologous blood donation in cancer patients," Jikoketsu Yuketsu, vol. 12, pp. 100-104, 1999 (Japanese).

[91] M. Azuma, M. Motomiya, and T. Toyota, "Effect of SeishinRenshi-In (TJ-111) on blood sugar levels of patients with non-insulin-dependent-diabetes-mellitus," Nihon Toyo Igaku Zasshi, vol. 45, pp. 339-344, 1994 (Japanese).

[92] S. Yamano, F. Sawai, T. Hashimoto, and K. Dohi, "Comparative effects between Dai-Saiko-to and elastase on lipid metabolism and cerebral circulation in patients with hyperlipidemia," Kampo to Saishin-Chiryo, vol. 4, pp. 309-313, 1995 (Japanese).

[93] J. Sasaki, A. Matsunaga, K. Handa et al., "Effect of daisaikoto on hyperlipidemia comparison with clinofibrate," Rinsho to Kenkyu, vol. 68, pp. 3861-3871, 1991 (Japanese).

[94] H. Ishida, T. Ohtake, H. Kurihara, and Y. Maruyama, "Clinical study on augmentative effect of Saiboku-to for anxiolytic and antidepressive action of diazepam," Pain Clinic, vol. 20, pp. 395-399, 1999 (Japanese).

[95] M. Yamagiwa and K. Fujita, "Effect of treatment using lansoprazole on patients with an abnormal sensation in the throat and concomitant heart burn," Jibi to Rinsho, vol. 53, pp. 109-115, 2007 (Japanese).
[96] T. Maruyama, "Goshuyu-to versus lomerizine hydrochloride in the prophylactic treatment of migraine headaches: an open crossover trial," Itami to Kampo, vol. 16, pp. 30-97, 2006 (Japanese).

[97] H. Kimura, T. Ohotake, and H. Ishikura, "Efficacy of shakuyakukanzoto for relieving facial spasm," Shindan to Chiryo, vol. 79, pp. 2505-2508, 1991 (Japanese).

[98] R. Sekine, H. Watanabe, M. Mimura, H. Inoue, F. Tobise, and A. Namiki, "The effects of Gosha-jinki-gan on the low back pain and lower limb pain caused by the lumber spine: a comparison of Gosha-jinki-gan with befotiamine," Itami to Kampo, vol. 13, pp. 84-87, 2003 (Japanese).

[99] H. Inoue, "Rapid effect of combination with shoseiryuto and eppikajutsuto for acute otitis media with effusion in adults," Jibi to Rinsho, vol. 47, pp. 361-366, 2001 (Japanese).

[100] S. Matsushita, S. Ueda, Y. Ohuchi et al., "Usefulness of chotosan(TJ-47) for relieving the accompanying symptoms and sequelae of cerebrovascular disease, chronic cerebrovascular insufficiency, or hypertension," Geriatric Medicine, vol. 33, pp. 1333-1341, 1995 (Japanese).

[101] Y. Akiyama, S. Ohno, T. Asaoka et al., "The combination therapy with sarpogrelate hydrochloride and Kampo medicine (Orengedoku-to or Toki-shakuyaku-san) for Raynaud's phenomenon," Nihon Toyo Igaku Zasshi, vol. 51, pp. 1101-1108, 2001 (Japanese).

[102] K. Fujimori, E. Suzuki, and F. Gejyo, "Comparison between Bakumondo-to (Mai men dong tang) and dextromethorphan hydrobromide in terms of effect on postinfectious cough: a pilot study," Nihon Toyo Igaku Zasshi, vol. 51, pp. 725-732, 2001 (Japanese).

[103] H. Kimoto and H. Kuroki, "The efficacy of combined oseltamivirphosphate and maoto for the treatment of influenza," Kampo Igaku, vol. 29, pp. 166-169, 2005 (Japanese).

[104] T. Kubo and H. Nishimura, "Antipyretic effect of Mao-to, a Japanese herbal medicine, for treatment of type A influenza infection in children," Phytomedicine, vol. 14, pp. 96-101, 2007.

[105] S. Kato, T. Matsuda, T. Nakajima, N. Kaneko, and K. Iwasaki, "Clinical significance of the combination therapy of smoking cessation and the traditional Kampo medicine, 'Qing Fei Tang (Seihaito)' in chronic obstructive plumonary disease," Kampo to Saishin-Chiryo, vol. 14, pp. 260-265, 2005 (Japanese).

[106] K. Tatsumi, N. Shinozuka, K. Nakayama, N. Sekiya, T. Kuriyama, and Y. Fukuchi, "Hochuekkito improves systemic inflammation and nutritional status in elderly patients with chronic obstructive pulmonary disease," Journal of the American Geriatrics Society, vol. 57, pp. 169-170, 2009.

[107] Y. Nishizawa, Y. Nishizawa, G. H. Gracy, F. Yoshioka, and S. Fushiki, "A randomized group-parallel comparative trial of the suppressive effect of Chinese traditional medicine, ShenMi-Tang (Shin-Pi-To), compared to sodium oramoylycate inhalation in improving subjective and objective symptoms in bronchial asthmatics," Jibi-Inkoka Tembo, vol. 47, supplement 1, pp. 20-27, 2004.

[108] Y. Nishizawa, Y. Nishizawa, F. Yoshioka, G. H. Gracy, and S. Fushiki, "Suppressive effect of Chinese traditional medicine, She-Bi-Tang (Shinpi To) on bronchospasms in aspirin-intolerant bronchial asthmatic patients-a randomized, group-paralleled comparative trial," Jibi-Inkoka Tenbo, vol. 46, pp. 3-14, 2003 (Japanese). 
[109] Y. Nishizawa, Y. Nishizawa, F. Yoshioka et al., "Clinical effect of a chinese traditional herbal medicine, Chai-po-tang (Japanese name: Saiboku-to) compared with clotiazepam in patients with bronchial asthmatics and anxiety disorder in multicenter randomized, comparative trial," Nihon Toyo Shinshin Igaku Kenkyu, vol. 17, pp. 20-27, 2002 (Japanese).

[110] Y. Nishizawa, Y. Nishizawa, F. Nagano et al., "Sparing effect of Saibokuto inhalation on inhaled beclomethasone dipropionate to halved of reduction of inhaled beclomethasone dipropionate-dose: well-controlled comparative study of Saiboku-To-inhalation and sodium cromoglycateinhalation," Jibi-Inkoka Tenbo, vol. 45, pp. 8-15, 2002 (Japanese).

[111] Y. Egashira and H. Nagano, "A multicenter clinical trial of TJ-96 in patients with steroid-dependent bronchial asthma. A comparison of groups allocated by the envelope method," Annals of the New York Academy of Sciences, vol. 685, pp. 580583, 1993.

[112] H. Mikamo and T. Tamaya, "Usefulness of Kampo medicine for the treatment of infections from the perspective of medical economics," Sanfujika Kampo Kenkyu no Ayumi, vol. 24, pp. 105-108, 2007 (Japanese).

[113] M. Umemoto, T. Nin, S. Miuchi, A. Negoro, and M. Sakagami, "Treatment of human dry mouth using various medicines," Jibiinkoka Rinsho, vol. 100, pp. 145-152, 2007 (Japanese).

[114] T. Yamada, K. Bessho, K. Murakami, S. Hori, T. Iizuka, and N. Segami, "Clinical evaluation of Sai-boku-to (Kampo medicine) for glossodynia," Shika Yakubutsu Ryoho, vol. 17, pp. 18-22, 1998 (Japanese).

[115] S. Kato, T. Nakajjima, T. Matsuda, N. Kaneko, and K. Iwasaki, "The effectiveness of the traditional Kampo Medicine, 'Banxia houpu tang (Hangekobokuto)' to respiratory disturbance by gastro esophageal reflux disease," Kampo to SaishiChiryo, vol. 14, pp. 333-338, 2005 (Japanese).

[116] A. Koide, "Establishment of new treatment strategy for nonerosive reflux disease (endoscopy-negative gastroesophageal reflux disease)-potential of rikkunshito," Medical Q, vol. 187, p. 1, 2006 (Japanese).

[117] K. Higuchi, T. Arakawa, K. Ando, Y. Fujiwara, T. Uchida, and T. Kuroki, "Eradication of Helicobacter pylori with a Chinese herbal medicine without emergence of resistant colonies," The American Journal of Gastroenterology, vol. 94, pp. 14191421, 1999.

[118] T. Yamaguchi and A. Koide, "Usefulness of Rikkun-shi-to (TJ-43), a Chinese herbal medicine, for the treatment of gastro-esophageal reflux disease (GERD)," Medical Science Digest, vol. 33, pp. 748-752, 2007 (Japanese).

[119] Y. Nishizawa, Y. Nishizawa, G. H. Gracy et al., "A prospective, multicenter, randomized, controlled study of kumibinroto on the aged dialysis patients," Kampo Kenkyu, vol. 388, pp. 132-138, 2004 (Japanese).

[120] O. Nakajima, M. Sone, K. Kurokawa et al., "The complemental treatment for chronic hepatitis C," Kagaku Ryoho Kenkyusho Kiyo, vol. 34, pp. 40-51, 2003 (Japanese).

[121] O. Nakajima, M. Sone, E. Onishi et al., "Preventive effects of shosaikoto on development from type C hepatitis to liver cirrhosis," Rinsho to Kenkyu, vol. 76, pp. 176-184, 1999 (Japanese).

[122] K. Tarao, "Prevention of HSS by anti-inflammatory agents in patients with chronic hepatitis C," Rinsho Shokaki Naika, vol. 22, pp. 961-969, 2007 (Japanese).
[123] M. Okuma, "Treatment of acne by Chinese drugs and external application," Wakan Iyaku Gakkaishi, vol. 10, pp. 131-134, 1993 (Japanese).

[124] Y. Nishizawa, Y. Nishizawa, F. Yoshioka, S. Nosaka, Y. Amakata, and Y. Amanomori, "The multicenter randomized comparative study of Kampo herbal medicine, Mai-MenDong-Tang (Japanese name Bakumondo-to) compared with bromhexine on salivary secretion in secondary Sjogren's syndrome," Itami to Kampo, vol. 14, pp. 10-17, 2004 (Japanese).

[125] Y. Nishizawa, Y. Nishizawa, F. Yoshioka et al., "Improving effect of Chinese traditional herb medicine Mai-Men-DongTang (Japanese name:Bakumondo-to) comparative with bromhexine hydrochloride of Sicca syndrome in especial salivary patients with secondary Sjoegren's syndrome in multicenter, well controlled, long-term comparative study," Nihon Daekisen Gakkai Shi, vol. 44, pp. 65-70, 2003 (Japanese).

[126] Y. Nishizawa, Y. Nishizawa, F. Yoshioka et al., "Long-term effects of traditional Chinese herbal medicine, Mai-MenDong-Tang (Japanese name: Bakumondo-To) compared with bromhexine, hydrochloride on Sicca syndrome, especially, salivary secretion in patients with primary Sjogren's syndrome: a multicenter, randomised well controlled groupparallel comparative trial study with bromhexine," Nihon Daekisen Gakkai Shi, vol. 43, pp. 62-66, 2002 (Japanese).

[127] Y. Hayashi, E. Saito, and O. Takahashi, "Usefulness of hachimijiogan for lumbar spinal stenosis," Geriatric Medicine, vol. 32, pp. 585-591, 1994 (Japanese).

[128] S. Maejima and Y. Katayama, "Spine and spinal cord diseases 2. Traditional Chinese medicines for the chronic lumbar pain," Kampo to Saishin-Chiryo, vol. 13, pp. 232-236, 2004 (Japanese).

[129] Y. Nishizawa, Y. Nishizawa, H. Yoshioka et al., "Efficacy and safety of Chinese traditional medicine, Niu-Che-Shen-QiWan (Japanese name: Goshajinki-gan) versus propiverine hydrochloride on health-related quality of life in patients with overactive bladder in prospective randomized comparative study," Kampo to Saishin-Chiryo, vol. 16, pp. 131-142, 2007 (Japanese).

[130] S. Iwabuchi, "Effect of kyuki-kyogai-to on stopping dysfunctional uterine bleeding-comparison with occidental hematostatic drug," Nihon Toyo Igaku Zasshi, vol. 50, pp. 883-890, 2000 (Japanese).

[131] K. Takamatsu, "Study of the usefulness of Kampo therapy for climacteric disorders-a randomized trial of the three major Kampo medicines for treatment of gynecological disease," Sanfujinka Kampo Kenkyu no Ayumi, vol. 23, pp. 35-42, 2006 (Japanese).

[132] T. Ushiroyama, A. Ikeda, K. Sakuma, and M. Ueki, "Comparing the effects of estrogen and an herbal medicine on peripheral blood flow in post-menopausal women with hot flashes: hormone replacement therapy and gui-zhi-fu-lingwan, a Kampo medicine," The American Journal of Chinese Medicine, vol. 33, pp. 259-267, 2005.

[133] A. Matsuo, K. Koike, A. Hoshina et al., "Effect of unkeito on menopausal women with depressive symptoms with ineffective hormone replacement therapy," Sanfujinka Kampo Kenkyu no Ayumi, vol. 22, pp. 70-74, 2005 (Japanese).

[134] H. Ota, "Positioning of Kampo therapy and hormone replacement therapy in treatment of climacteric disorders," Sanfujinka Kampo Kenkyu no Ayumi, vol. 18, pp. 21-29, 2001 (Japanese).

[135] N. Ushiroyama, K. Sakuma, S. Nosaka, Y. Yamashita, H. Kametani, and R. Araki, "Clinical efficacy of kyukikyogaito 
or imminent abortion with uterine hemorrhage," Sanfujinka Kampo Kenkyu no Ayumi, vol. 23, pp. 100-103, 2006 (Japanese).

[136] H. Wada, K. Wada, and S. Motoyama, "Effectiveness of Kyukichoketsuin on postpartum condition," Sanfujinka no Sekai, vol. 55, pp. 1057-1061, 2003 (Japanese).

[137] K. Sakuma, T. Ushiroyama, D. Akise et al., "Clinical efficacy of Kyuki-choketsu-in, a Japanese traditional herbal medicine, on the restration of postpartum psycho-physical condition," Sanfujinka no Shinpo, vol. 54, pp. 80-86, 2002 (Japanese).

[138] Y. Takushima and H. Inoguchi, "Study on usefulness of kyukichoketsuin for control of puerperium-comparison with methylergometrine maleate (the first report)," Progress in Medicine, vol. 21, pp. 1535-1542, 2001 (Japanese).

[139] Y. Nishizawa, Y. Nishizawa, F. Yoshioka et al., "Beneficial effect of Chinese traditional herbal medicine, Mai-MenDong-Tang (Japanese name:Bakumondo-to) on acute pain in patients with acute internal medical disease: antitussive effect on elderly patients with postinfectious persistent coughs, prospective, multicenter, randomized comparative trial between Mai-Men-Dong-Tang and Forminoben Hydrochloride," Itami to Kampo, vol. 13, pp. 12-21, 2003 (Japanese).

[140] Y. Motoo, H. Mori, K. Ohtsubo, Y. Yamaguchi, H. Watanabe, and N. Sawabu, "Herbal medicine Ninjinyoeito ameliorates ribavirin-induced anemia in chronic hepatitis C: a randomized controlled trial," World Journal of Gastroenterology, vol. 11, pp. 4013-4017, 2005.

[141] H. Hushiki, A. Saeki, and A. Shiozaki, "Attempt to reduce adverse reactions associated with oral iron preparation for anemia in pregnancy by combination with rikkunshito (TJ43)," Sanfujinka Kampo Kenkyu no Ayumi, vol. 20, pp. 138139, 2003 (Japanese).

[142] M. Imazato, S. Kai, K. Koizumi et al., "A clinical study of Shakuyaku-Kanzo-to (Kampo) as a preparation for double contrast barium enema," Kampo Igaku, vol. 22, pp. 87-92, 1998 (Japanese).

[143] H. Yokota, H. Kanazawa, T. Kondo et al., "New colon preparation using the Kampo herb method (Daio-kanzoto)," Current Therapy, vol. 8, pp. 805-810, 1990 (Japanese).

[144] Y. Saida, M. Takase, C. Okumura et al., "Efficacy of combined use of shakuyakukanzoto in pretreatment for large bowel endoscopy prospective randomized trial," Nihon Daicho Kensa Gakkai Zasshi, vol. 20, pp. 34-37, 2003 (Japanese).

[145] N. Ohnishi, Y. Yonekawa, T. Fumihara et al., "Studies on interactions between traditional herbal and Western medicines, II. Lack of pharmacokinetic interaction between Shoseiryu-to and carbamazepine in healthy volunteers," TDM Kenkyu, vol. 16, pp. 399-404, 1999.

[146] Y. Saida, Y. Sumiyama, J. Nagao, Y. Nakamura, and M. Katagiri, "Dai-kenchu-to, a herbal medicine, improves precolonoscopy bowel preparation with polyethylene glycol electrolyte lavage: results of a prospective randomized controlled trial," Digest Endoscopy, vol. 17, pp. 50-53, 2005.

[147] N. Sugihara, "Effectiveness of shakuyaku-kanzo-to as a pretreatment for upper digestive tract endscopic examination," Kampo Shinryo, vol. 18, pp. 17-19, 1999 (Japanese).

[148] M. Ai, T. Yamaguchi, K Mitsuhashi et al., "Objective assessment of the antispasmodic effect of shakuyaku-kanzoto (TJ-68), a Chinese herbal medicine, on the colonic wall by direct spraying during colonoscopy," World Journal of Gastroenterology, vol. 12, pp. 760-764, 2006 (Japanese).
[149] T. Mizukami, K. Maruyama, H. Yamauchi, H. Imaeda, H. Ogata, and T. Hibi, "Assessment of antispasmodic effect of herbal medicine, shakuyakukanzoto (TJ-68) on colonoscopy-using colonoscopy insertion technique 'collapsing method'" Kampo to Saishin-Chiryo, vol. 15, pp. 6976, 2006.

[150] V. Fønnebø, S. Grimsgaard, H. Walach et al., "Researching complementary and alternative treatments-the gatekeepers are not at home," BMC Medical Research Methodology, vol. 7, Article ID 7, 2007.

[151] C. Becker-Witt, R. Lüdtke, T. E. R. Weißhuhn, and S. N. Willich, "Diagnoses and treatment in homeopathic medical practice," Forschende Komplementarmedizin und Klassische Naturheilkunde, vol. 11, no. 2, pp. 98-103, 2004.

[152] C. M. Witt, R. Lüdtke, R. Baur, and S. N. Willich, "Homeopathic medical practice: long-term results of a cohort study with 3981 patients," BMC Public Health, vol. 5, Article ID 115, 2005.

[153] C. M. Witt, R. Ludtke, N. Mengler, and S. N. Willich, "How healthy are chronically ill patients after eight years of homeopathic treatment? results from a long term observational study," BMC Public Health, vol. 8, p. 413, 2008.

[154] "Center for Kampo Medicine, Keio University School of Medicine," June 2009, http://web.sc.itc.keio.ac.jp/kampo/vc/ index.html.

[155] K. Terasawa, "Evidence-based reconstruction of Kampo medicine: part III-how should Kampo be evaluated?" Evidence-Based Complementary and Alternative Medicine, vol. 1, pp. 219-222, 2004.

[156] H. Kobayashi, K. Takahashi, N. Mizuno, H. Kutsuna, and M. Ishii, "An alternative approach to atopic dermatitis: part II-summary of cases and discussion," Evidence-Based Complementary and Alternative Medicine, vol. 1, pp. 145-155, 2004.

[157] H. Walach, W. Haeusler, T. Lowes et al., "Classical homeopathic treatment of chronic headaches," Cephalalgia, vol. 17, no. 2, pp. 119-126, 1997.

[158] H. Kobayashi, M. Ishii, S. Takeuchi et al., "Efficacy and safety of a traditional herbal medicine, Hochu-ekki-to in the longterm management of Kikyo (delicate constitution) patients with atopic dermatitis: a 6-month, multicenter, doubleblind, randomized, placebo-controlled study," EvidenceBased Complementary and Alternative Medicine, 2008.

[159] C. M. Witt, "Efficacy, effectiveness, pragmatic trialsguidance on terminology and the advantages of pragmatic trials," Forschende Komplementarmedizin, vol. 16, no. 5, pp. 292-294, 2009.

[160] H. Kobayashi, K. Takahashi, N. Mizuno, H. Kutsuna, and M. Ishii, "An alternative approach to atopic dermatitis: part I-case-series presentation," Evidence-Based Complementary and Alternative Medicine, vol. 1, pp. 49-62, 2004.

[161] R. Crow, H. Gage, S. Hampson, J. Hart, A. Kimber, and H. Thomas, "The role of expectancies in the placebo effect and their use in the delivery of health care: a systematic review," Health Technology Assessment, vol. 3, pp. 1-96, 1999.

[162] M. V. Mondloch, D. C. Cole, and J. W. Frank, "Does how you do depend on how you think you'll do? A systematic review of the evidence for a relation between patients' recovery expectations and health outcomes," Canadian Medical Association Journal, vol. 165, pp. 174-179, 2001.

[163] K. Linde, C. M. Witt, A. Streng et al., "The impact of patient expectations on outcomes in four randomized controlled trials of acupuncture in patients with chronic pain," Pain, vol. 128 , no. 3 , pp. 264-271, 2007. 


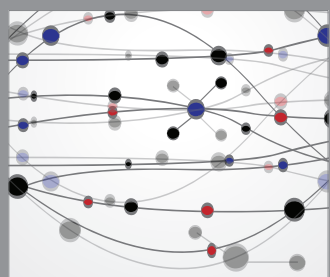

The Scientific World Journal
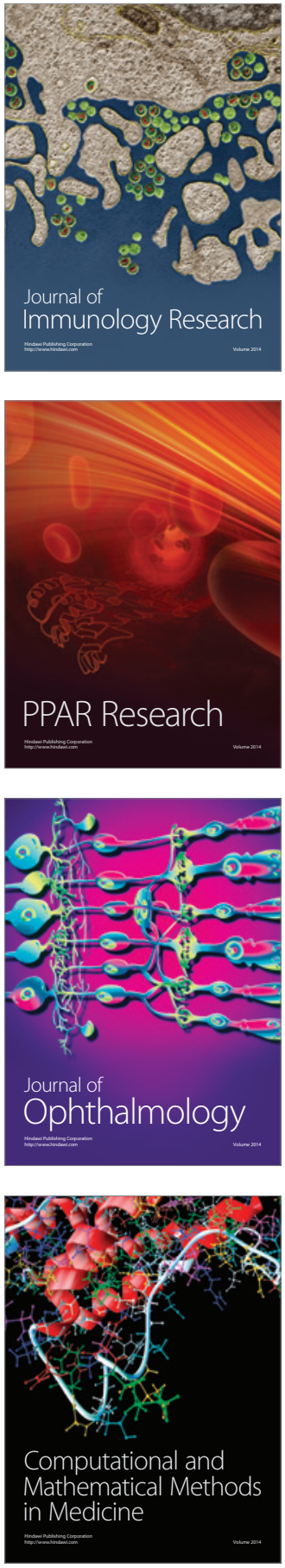

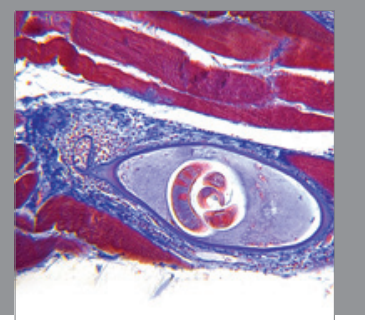

Gastroenterology

Research and Practice
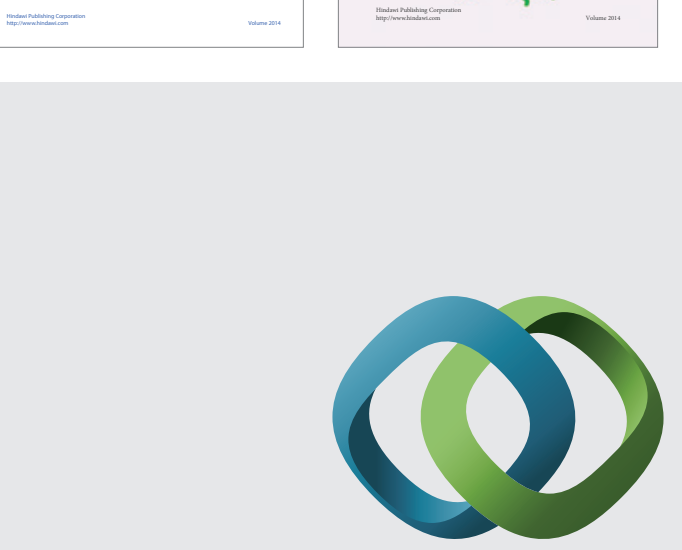

\section{Hindawi}

Submit your manuscripts at

http://www.hindawi.com
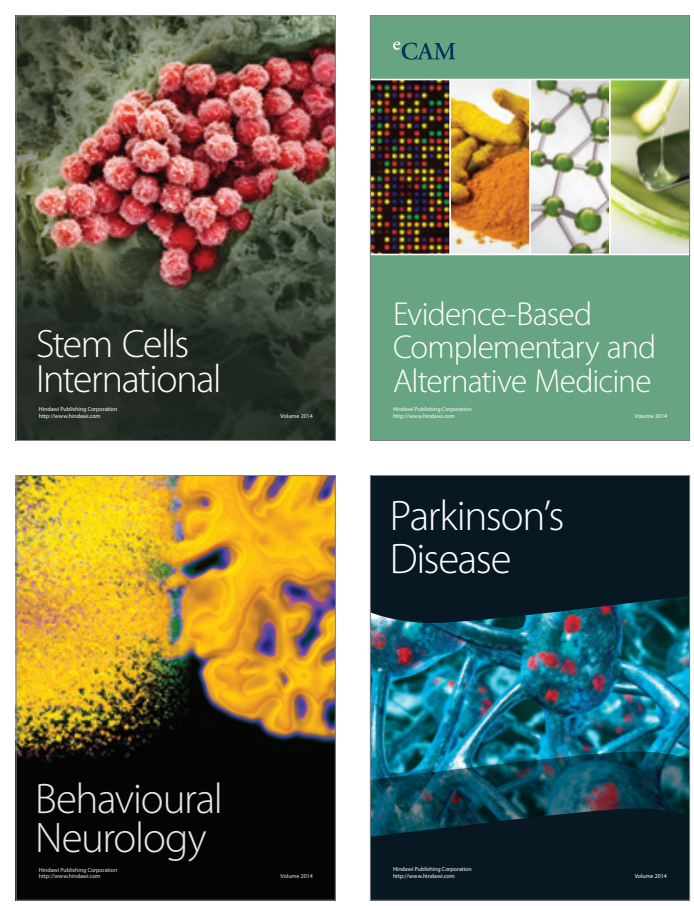

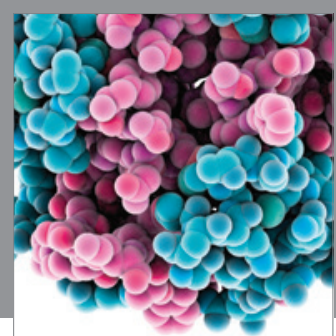

Journal of
Diabetes Research

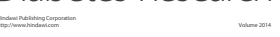

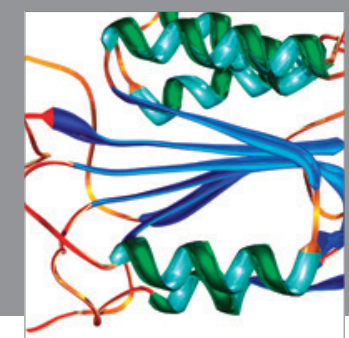

Disease Markers
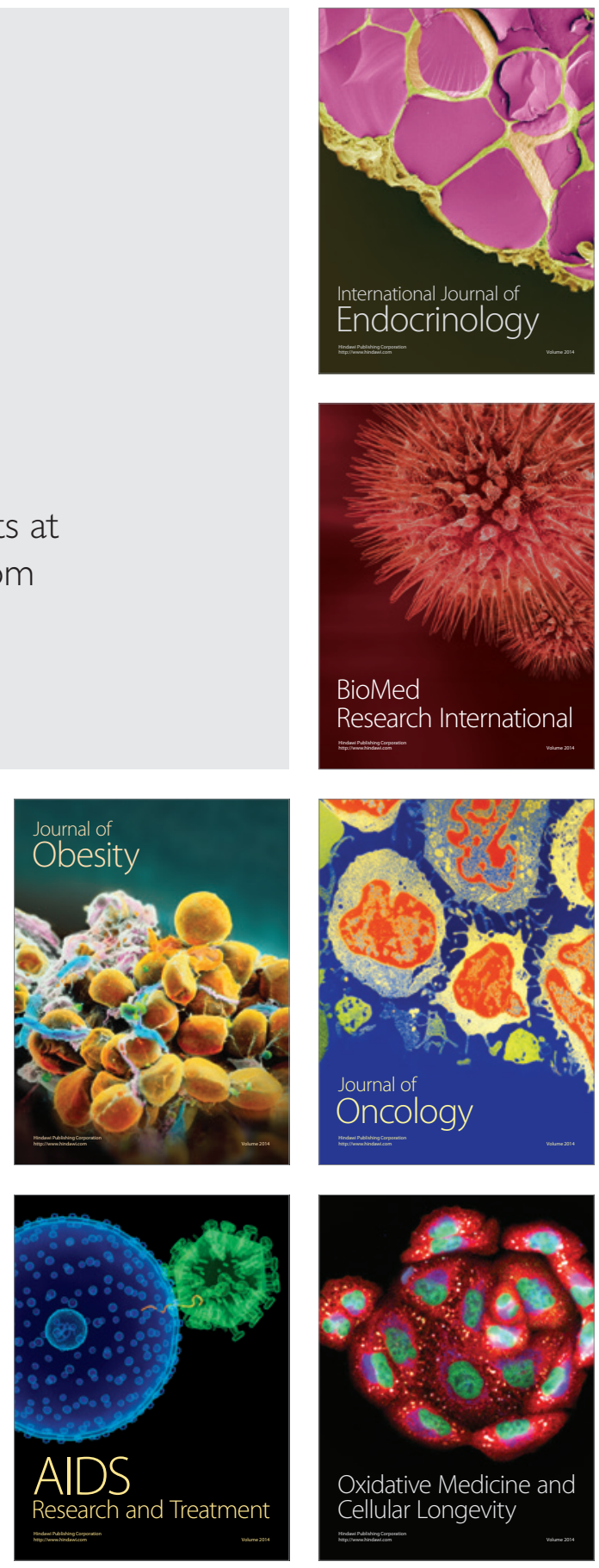